WP EN2016-09

\title{
Integrating short term variations of the power system into integrated energy system models: A methodological review
}

Seán Collins, Paul Deane, Kris Poncelet, Evangelos Panos, Robert Pietzcker, Erik Delarue and Bryan Ó Gallachóir

TME WORKING PAPER - Energy and Environment Last update: April 2017

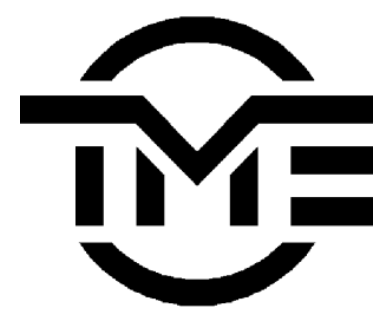

An electronic version of the paper may be downloaded from the TME website:

http://www.mech.kuleuven.be/tme/research/ 


\section{Integrating short term variations of the power system into integrated}

energy system models: A methodological review

Seán Collins ${ }^{a, b, c}{ }^{*}$, Paul Deane ${ }^{a, b, c}$, Kris Poncelet ${ }^{d, e, f}$, Evangelos Panos ${ }^{g}$, Robert Pietzcker ${ }^{h}$, Erik Delarue ${ }^{\text {d,e }}$, Brian Ó Gallachóir ${ }^{a, b, c}$

a) Environmental Research Institute, University College Cork, Cork, Ireland

b) School of Engineering, University College Cork, Cork, Ireland

c) MaREI Centre, Environmental Research Institute, University College Cork, Cork, Ireland

d) Department of Mechanical Engineering, KU Leuven, Leuven, Belgium

e) EnergyVille, Genk, Belgium

f) VITO, Mol, Belgium

g) Paul Scherrer Institut, Villigen, Switzerland

h) Potsdam Institute for Climate Impact Research (PIK), Potsdam, Germany

*Corresponding Author

Contact Information: Telephone: +353 (0)21 4901959

Fax: + 353 (0)21 4901970

Email: sean.collins@umail.ucc.ie

Address: Environmental Research Institute, Lee Road, Cork, Ireland

\section{Abstract}

It is anticipated that the decarbonisation of the entire energy system will require the introduction of large shares of variable renewable electricity generation into the power system. Long term integrated energy systems models are useful in improving our understanding of decarbonisation but they struggle to take account of short term variations in the power system associated with increased variable renewable energy penetration. This can oversimplify the ability of power systems to accommodate variable renewables and result in mistaken signals regarding the levels of flexibility required in power systems. Capturing power system impacts of variability within integrated energy system models is challenging due to temporal and technical simplifying assumptions needed to make such models computationally manageable. This paper addresses a gap in the literature by reviewing prominent methodologies that have been applied to address this challenge and the advantages \& limitations of each. The methods include soft linking between integrated energy systems models and power systems models and improving the temporal and technical representation of power systems within integrated energy systems models. Each methodology covered approaches the integration of short term variations and assesses the flexibility of the system differently. The strengths, limitations, and applicability of these different methodologies are analysed. This review allows users of integrated energy systems models to select a methodology (or combination of methodologies) to suit their needs. In addition, the analysis identifies remaining gaps and shortcomings.

\section{Keywords}

Energy system planning; Integration of renewable energy sources; Technical Resolution; Temporal resolution; Power systems 


\section{Highlights}

- Long term energy system modelling challenges identified for the power sector

- State-of-the-art methodologies for integrating the challenges related to the integration of variable renewables are presented

- Comparison of methodologies succinctly exposes the strengths \& limitations of each respective methodology

\section{Introduction}

The transition to a low-carbon energy system is expected to require the electricity sector to integrate large amounts of variable renewable energy sources (VRES) [1-4]. The instantaneous electricity generation by VRES is highly intermittent, location specific and only predictable to a limited extent. A massive penetration of VRES, therefore, has a strong impact on the operation of the power system [5-9]. Capturing the economic and technical challenges related to a large-scale penetration of VRES, therefore, requires modelling the variability in system load and renewable generation, the limited flexibility of thermal units and the spatial smoothing of the variability. This requires models with a high level of temporal, technical and spatial detail.

Long-term planning models have been applied frequently to analyse scenarios for the evolution of the energy system over multiple decades. Due to computational restrictions, the level of temporal, technical and spatial detail in these models is typically low. In contrast, operational power system models focus on the operations of the power system using a high level of detail but do not consider its long-term evolution.

Multiple authors have recently analysed the impact of temporal detail [10-16], technical detail [10, 11, 17-20] and spatial detail [21-23] employed in long-term planning models. Depending on the representation of integration challenges, low levels of detail can either favour or disfavour VRES: For high penetrations of VRES, If electricity is treated as a homogeneous good or only a low number of averaged time-slices is used, the low level of detail leads to an overestimation of the value of baseload technologies and VRES, while the value of flexible generation technologies with higher generation costs is underestimated [10]. In contrast, if a model uses rather crude representations of integration challenges such as upper limits on VRES shares or fix backup requirements, the low level of detail can overly restrict the deployment of VRES compared to more detailed representations [24]. As a result, the cost of achieving ambitious greenhouse gas emission reduction targets can be either significantly under- or overestimated.

Moreover, the importance of capturing critical elements of power system operation for planning a reliable and adequate power system is analysed in [25-29], making clear that a reliable operation of the power system cannot be guaranteed for the scenarios generated by current long-term planning models. As such, Pfenninger et al [30] consider 'resolving time and space' to be the main challenge for energy system optimization models. For such long term modelling analyses it is also critical from an operational perspective to capture the current state of play and development of technologies so as to ensure a realistic trajectory of future technology development is considered [31-35].

Bridging the gap between highly-detailed operational power system models and long-term planning models has become an active field of research, in view of the challenge of the transition to a less 
carbon-intensive energy system. Numerous methodologies to bridge this gap have recently been developed [10, 24, 30, 36, 37].

This paper presents a review of prominent methodologies developed to better capture the economic and technical challenges related to the integration of VRES in two families of long-term planning models, namely long-term energy system optimization models (ESOMs) usually focusing on country-level (or group of countries, e.g. EU-level) scenarios for the next decades, and Integrated Assessment Models (IAMs), which focus on global long-term scenarios for the full $21^{\text {st }}$ century. The strengths, limitations, and applicability of these different methodologies described in the literature are analysed. This analysis allows users of long-term planning models to select a methodology (or combination of methodologies) to suit their needs. In addition, the analysis exposes the needs for further research.

The remainder of this paper is organized as follows. First, Section 2 identifies the problem space by presenting a comprehensive overview of the different types of models and the level of temporal, technical and spatial detail typically employed in these models. Second, Section 3 presents the different methodologies developed in the literature for improved capturing of the economic and technical challenges related to the integration of VRES in planning models. The strengths and limitations of each approach are discussed in detail. Finally, main conclusions are formulated in Section 4.

\section{Overview of energy modelling tools}

This section first presents a brief description of the models considered in this paper, i.e., operational power system models, energy system optimization models and integrated assessment models. Subsequently, the level of temporal, technical and spatial detail typically used in each of these models is discussed.

\section{1. Operational power system models}

Operational power system models analyse the operations of a given power system, i.e., investment decisions are not considered. While there are large differences in the focus and applications of operational power system models [38], the focus of this work is on unit commitment and economic dispatch (UCED) models. UCED models determine for every time step within a certain time horizon which units should be online and how much each unit should be generating in order to minimize the cost of supplying a given demand for electricity. Detailed technical constraints, such as the minimal operating level, restricted ramping rates, minimum up and down times, start-up costs and efficiency losses during part-load operation are accounted for on a unit by unit level. Properly accounting for the minimal operating level requires tracking the commitment status of individual units. As such, most current UCED models rely on mixed-integer linear programming (MILP). Due to a large amount of integer variables, solving UCED models can be computationally challenging. The time horizon of UCED models is typically restricted to one day up to one year. This time horizon is disaggregated into different time steps with a resolution in the range of 5 minutes up to one hour. Prominent examples of UCED models include PLEXOS [39], LUSYM [40], GTMax [41], ORCED [42] and EnergyPLAN [43].

While UCED models allow analysing the operation of the power system in detail, these models do not allow to consider the (cost-optimal) evolution of the installed generation capacity. Moreover, the scope of these models is restricted to the power system. Interactions with other energy sectors 
such as the heating and transport sector are generally modelled by exogenously specifying the demand for electricity.

\section{2. Long-term energy system optimization models (ESOMs)}

ESOMs are used mainly to generate scenarios for the long-term evolution of the energy system. As such, ESOMS compute the investments and operation of the energy system that result in a partial equilibrium of the energy system, i.e., ESOMs simultaneously compute the production and consumption of different commodities (fuels, materials, energy services) and their prices in such a way that at the computed price, production exactly equals consumption. This equilibrium is referred to as a partial equilibrium since the scope of ESOMs is restricted to the energy system (comprising the power sector, transport sector, heating sector, etc.), being merely a part of the overall economic system. To compute this partial equilibrium, ESOMs rely on the fact that this equilibrium is established when the total surplus is maximized (or when total cost is minimized in case of an inflexible demand). Optimization techniques, such as linear programming, are applied to retrieve the investments, production and consumption patterns as well as trade flows yielding a maximal surplus. In contrast to some of the IAMs discussed below, partial equilibrium models are bottom-up models, meaning that each specific sector is composed of multiple explicitly defined technologies which are interlinked by their input and output commodities. Regarding the geographical scope, ESOMs are generally applied to countries or regions, but can also be applied on a city level. The time horizon spanned is generally multiple decades. The main strength of ESOMs is that these models provide a comprehensive description of possible scenarios for the transition of the energy system by considering the inter-temporal, inter-regional and inter-sectoral relationships. A limitation of ESOMs that are applied to only one country is that they ignore the potential benefit of international cooperation for the integration of VRES via expanded transmission grids. Well-known examples of ESOMS are MARKAL/TIMES [44], MESSAGE [45] and REMIX [46].

\section{3. Integrated assessment models}

IAMs and ESOMs share many characteristics and can consist of the same modelling frameworks ${ }^{1}$. The main difference is their aim and scope: ESOMs typically focus on near-term energy system transformations in individual countries or regions, whereas IAMs complement socio-economic modelling with natural sciences to analyse long-term interdisciplinary questions, typically of a global scope, such as assessing policies to mitigate climate change [50,51]. To address these questions, IAMs need to represent not only the different energy demand sectors such as transport, residential, and industrial energy use, but also topics like economic growth, resource availability, and land-userelated emissions. These differences in temporal, spatial and topical coverage imply that IAMs require higher temporal and geographical aggregation compared to ESOMs in order to keep computational complexity at a manageable level.

\footnotetext{
${ }^{1}$ The IAMs ETSAP-TIAM and TIAM-UCL use the TIMES modelling framework, while IIASA's MESSAGE IAM model is built on a MESSAGE modelling framework with additional non-energy sector modules. MESSAGE modelling framework is distributed by the IAEA for national and regional planning purposes. [47] ETSAP. http://www.iea-etsap.org/web/applicationGlobal.asp 2016, [48] UCL. https://www.ucl.ac.uk/energymodels/models/tiam-ucl/\#etsap-tiam. 2016, [49] Messner S, Schrattenholzer L. MESSAGE-MACRO: linking an energy supply model with a macroeconomic module and solving it iteratively. Energy. 2000;25:267-82.
} 
IAMs come in a variety of types: some IAMs like MESSAGE [52], TIAM [47, 48], POLES [53], IMAGE [54] or GCAM [55] originate from a bottom-up approach with relatively high technological detail, others like AIM/CGE [56], MERGE [57], or EPPA [58] came from a more top-down approach with stronger focus on economic interactions and less on technological detail. In the last decades, most of these models have evolved to become more hybrid in their approach, merging technology detail with macro-economic feedbacks, a feature also found in more recently developed models like WITCH [59] or REMIND [60].

To offset the low temporal detail and still represent the variability of load and VRES, most IAMs have introduced additional equations and constraints that try to mimic the effect of variability in a stylized way. Examples include implementing hard upper bounds on VRES shares, using inflexible substitution functions, requiring a fixed amount of backup per unit of VRES capacity, adding integration cost mark-ups, or implementing peak capacity equations. [4, 24, 61-64]

\subsection{Overview of model simplifications}

This section describes the main model simplifications which are made in ESOMs and IAMs in terms of the level of temporal, spatial and technical detail used to describe the electric energy system. These simplifications are in contrast with the high resolution modelling of operational power system models that are of a narrower scope. Insufficient temporal, technical or spatial representation can provide incorrect signals regarding the potential and value of different technologies leading to an under- or overestimation ${ }^{2}$ of the effort required to transition to an energy system with high proportions of renewable power generation.

Different modelling tools employ different levels of temporal, technical and spatial detail. An overview of the level of detail typically employed in each of these models is presented in in Figure 1, these are further discussed in the sections 2.4.1, 2.4.2 and 2.4.3.

2 In IAMs and ESOMs that represent VRES integration challenges in a stylized way, the lack of detail can lead to an overestimation of the effort if the representations are overly restrictive, e.g. by being parameterized based on local time series data that does not represent the potential pooling effect of grid expansion [24] Pietzcker RC, Ueckerdt F, Carrara S, De Boer H-S, Després J, Fujimori S, et al. System integration of wind and solar power in Integrated Assessment Models: a cross-model evaluation of new approaches. Submitted to Energy Economics. 2016.. 


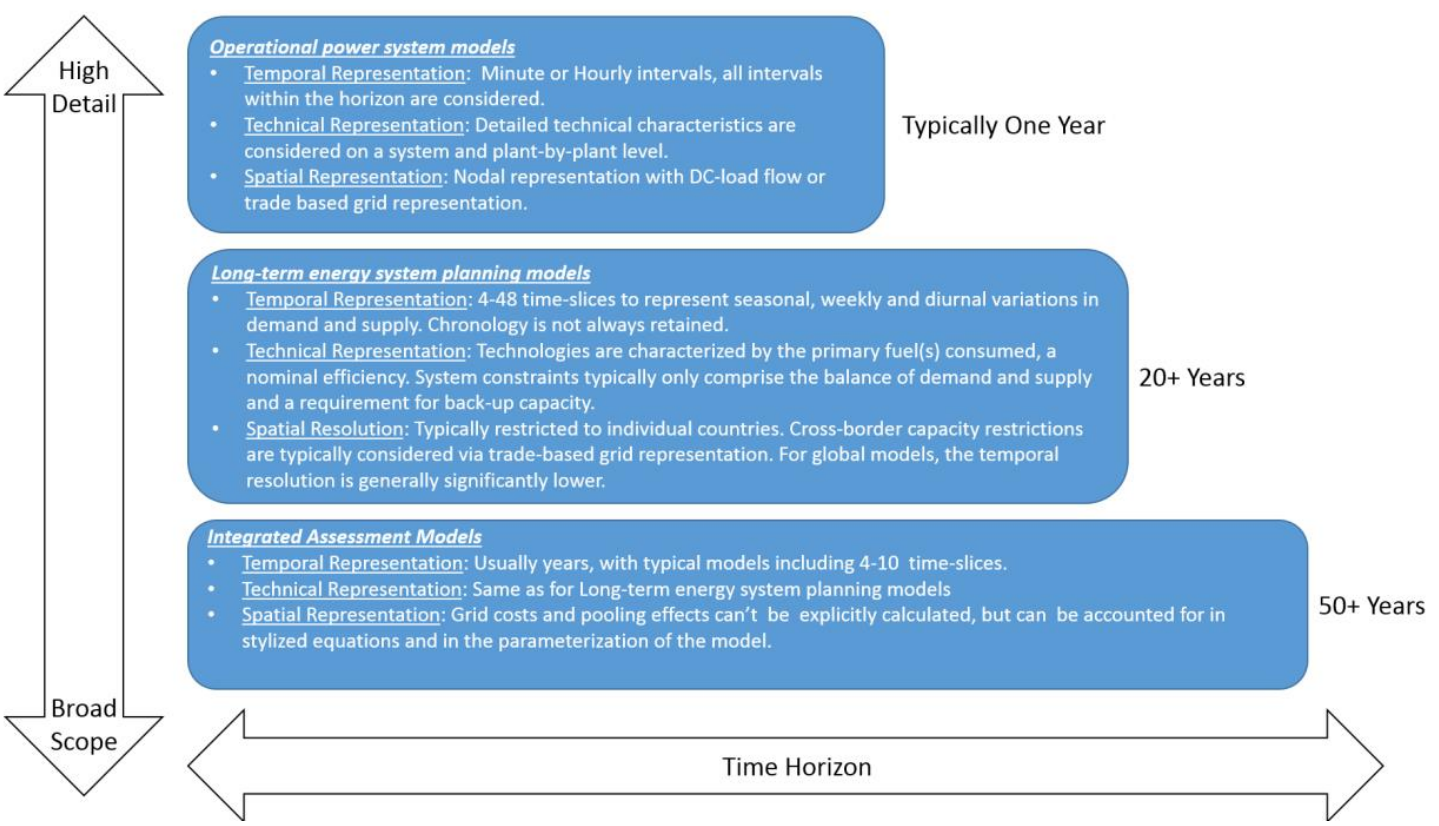

Figure 1 - Comparison of the level of detail of the model types considered in this analysis

\subsubsection{Temporal Representation}

In ESOMs, the considered time horizon is divided into a number of multi-year periods. Each of these periods is represented by a single year, the so-called milestone year. This milestone year is in turn subdivided into a number of so-called time-slices which represent seasonal, weekly and/or diurnal variations in demand and supply. In most ESOMs, the number of time-slices used and their definition can be determined freely by the user. However, the number of time-slices used typically lies in the range 4-48. Whether or not chronology is retained depends on how the time-slices are defined. A frequently occurring time-slice division uses 12 time-slices to distinguish between day, night and peak hours for four seasons. Examples of models using this time-slice division are the Irish TIMES model [65] and the JRC-EU-TIMES model [66]. Recently, multiple authors have investigated the impact of the stylized temporal representation and have experimented with different ways of creating time-slice divisions by increasing the number of time-slices and/or changing the way these time-slices are defined. A detailed discussion of the impact of the stylized temporal representation in ESOMs and different approaches for setting up the time-slice division can be found in Section 3.2.1.

Due to the large scope of IAMs, the level of temporal detail employed in these models is usually lower than in most ESOMs, i.e., the temporal resolution is generally one or several years, although some models like TIMER have as much as 10 time-slices per year. As aforementioned in section 2.3, many IAMs represent the effect of temporal variability in a stylized fashion, for these stylized representations, an accurate parameterization is of fundamental importance due to its impact on results. In [24] it is found that many of the older parameterizations overly restrict the deployment of VRES compared to newer representations based on better data and more detailed bottom-up analysis. One advanced methodology for representing a number of variability effects in an aggregated way will be discussed in Section 3.2.3. 


\subsubsection{Technical Representation}

In contrast to UCED models, ESOMs operate on a technology-type level and do not consider the operation of individual units. Hence, their load-following constraints and cycling costs are generally not explicitly accounted for [10]. Moreover, as modelling detailed load-following constraints such as ramping rate restrictions requires chronological data at a sufficiently high resolution, the possibilities to integrate technical constraints are dependent on the temporal representation, i.e., the time-slice division [10]. Hence, from a technology perspective, the technological detail is typically restricted to the specification of the efficiency and availability of different generation technologies, while flexibility restrictions are generally not accounted for.

Detailed technical constraints are not considered in IAMs. Similar to the level of temporal detail, additional constraints and parametrizations are used to account for the impact of technical constraints in a stylized fashion. This is also true in the case of ESOMs where technical details are often represented in a stylized way. Such as nuclear plants which are frequently defined on the seasonal time slice level.

\subsubsection{Spatial Representation}

The spatial scope and resolution are important to analyse trade flows and capture the impact of network-related constraints between regions. Both in ESOMs and IAMs, a set of regions is considered, rather than a more detailed nodal level. Hence, these models are currently not capable of accurately reflecting the impact of transmission network constraints and can encounter challenges in representing the distributed nature of VRES generation.

In ESOMs, the modelling of transmission networks is generally restricted to incorporating the limited capacities of cross-border transmission lines. In addition, the grid representation is typically tradebased. This means that Kirchhoff's voltage law does not need to be respected and there are no differences between $A C$ and $D C$ lines. This is in contrast to the DC load flow grid representation commonly used in UCED models [40].

Given the regional nature of ESOMs and IAMs, typically without low level nodal disaggregation, the benefits associated with spatial smoothing of VRES generation are challenging to account for. This becomes increasingly important with an increasing penetration of VRES because the correlation between the output of power at different renewable generation sites and from different renewable resources can strongly impact the overall variability and uncertainty of the residual load [60]. 


\section{State of the Art Methodologies}

This section describes different methodologies that aim to better capture the economic and technical challenges related to the integration of VRES. The methodologies described can be classified into two categories: direct integration and soft-linking model coupling methodologies. Fundamental differences between these categories of methodologies exist. The direct integration methodologies aim to improve the representation of VRES and their impact on the power system by directly improving the temporal, technical and/or spatial representation in the ESOM/IAM, or by introducing additional equations that mimic the effects of higher temporal, technical or spatial detail. In contrast, soft-linking methodologies recognize the limitations of using a single allencompassing model. In these methodologies, a soft-link between the ESOM/IAM, having a limited level of temporal and technical detail, and a dedicated UCED model is established.

The following sections present an overview of the applications of these different methodologies as well as their respective strengths and limitations. First, Section 3.1 describes the soft-linking methodologies for ESOMs and IAMs. Next, Section 3.2 and 3.3 present direct integration methodologies for ESOMs and IAMs respectively.

\subsection{Soft-linking ESOMs/IAMs to an operational power system model}

In this methodology, the power system as derived by an ESOM/IAM is used as input for an operational power systems model (i.e., UCED model), which re-computes the operations of this power system using a high level of temporal and technical detail. By analysing the power sector results from the ESOM/IAM in greater temporal and technical detail using the UCED model, this methodology aims to gain additional insights with regard to the operation of the resulting power system. More specifically, it allows more accurate calculations of the expected operational cost, the expected generation mix and corresponding greenhouse gas emissions, the need for curtailment of renewable energy and the reliability of the power system. In addition, the role that different generation technologies play in providing the flexibility required to balance demand and supply can be analysed [11].

The main methodological difference in different soft-linking methodologies described in the literature are found in the way the information provided by the UCED model is used. In this regard, we can distinguish between uni-directional and bi-directional soft-linking methodologies. In unidirectional soft-linking methodologies, there is no direct link from the UCED model to the ESOM/IAM, i.e., the UCED model is only used to provide additional information and as a check on the results provided by the ESOM/IAM. In bi-directional soft-linking methodologies, the information provided by the UCED model is used to systematically adapt certain parameters and/or add certain constraints in the ESOM/IAM. In an iterative procedure, both models are executed repeatedly until convergence between both models is obtained. Bi-directional soft-linking poses additional difficulties but allows to move closer to the globally optimal solution, i.e., the solution that would have been found if the ESOM/IAM could have been solved with high levels of temporal, technical and spatial detail. Hence, the added value of using a bi-directional soft-linking methodology increases as the results provided by the ESOM/IAM and the UCED diverge more strongly (and the solution of the ESOM/IAM drifts away from the global optimal solution). As shown by multiple authors, the divergence between the results provided by ESOMs and UCED models increases with the penetration of VRES in the power system $[10,12,15,20]$, which indicates that bi-directional softlinking methodologies are especially useful for modelling scenarios with very high shares of VRES. 
It is important to note that in order to employ the soft-linking methodology correctly, both the ESOM/IAM and the UCED models should share certain common inputs, in particular, the time series for the electricity demand and renewable generation to ensure comparable model results. An example of a detailed step-by-step uni-directional soft-linking methodology is presented in [11]:

1. Define the scenario and time horizon of the analysis and execute the ESOM/IAM.

2. For a specific year of interest, extract the electricity generation portfolio, fuel prices and carbon prices from the ESOM/IAM and populate the UCED model with this data. Include additional technical parameters, such as minimum stable generation levels, ramp rates, start costs, failure rates and maintenance rates, in the UCED model.

3. Convert the annual electricity demand time series from the ESOM/IAM to a chronological time series with hourly or lower resolution. This is done through taking a historical demand time series and scaling using quadratic optimisation so as the annual demand and peak demand for electricity are equal to the demand from the ESOM/IAM. In addition, use highresolution time series for VRES electricity generation based on the installed capacity and available historical generation time series or resource data (e.g., wind speed or solar irradiance data) for each region.

4. Initially run the UCED model for the target year using the high-resolution time series without any additional technical constraints such as minimum stable generation, ramp rates or start costs to demonstrate the impact of increased temporal detail within the model.

5. As next step, run the model with increasing levels of technical detail in order to determine the impacts of these technical constraints on the model results.

6. Contrast results between the models, identify differences and scrutinise the reliability and flexibility of the power system. Analyse the role that different generation technologies play in system operation.

7. Determine the implications of low production years for VRES modes of generation, such as wind and solar, on the reliability of the derived portfolio from the energy system model by running the power systems model with a number of different years of production profiles.

This uni-directional soft-linking methodology is illustrated in Figure 2 for an example where a TIMES ESOM with the target year of 2030 is soft-linked to the PLEXOS UCED model to analyse the results for the year 2020 .

For a bi-directional soft-link, an additional step is required in the methodology:

8. Use the insights gained from the results comparison to introduce constraints into the ESOM/IAM model to take account of the power system operation characteristics that are not readily captured within the ESOM/IAM. 


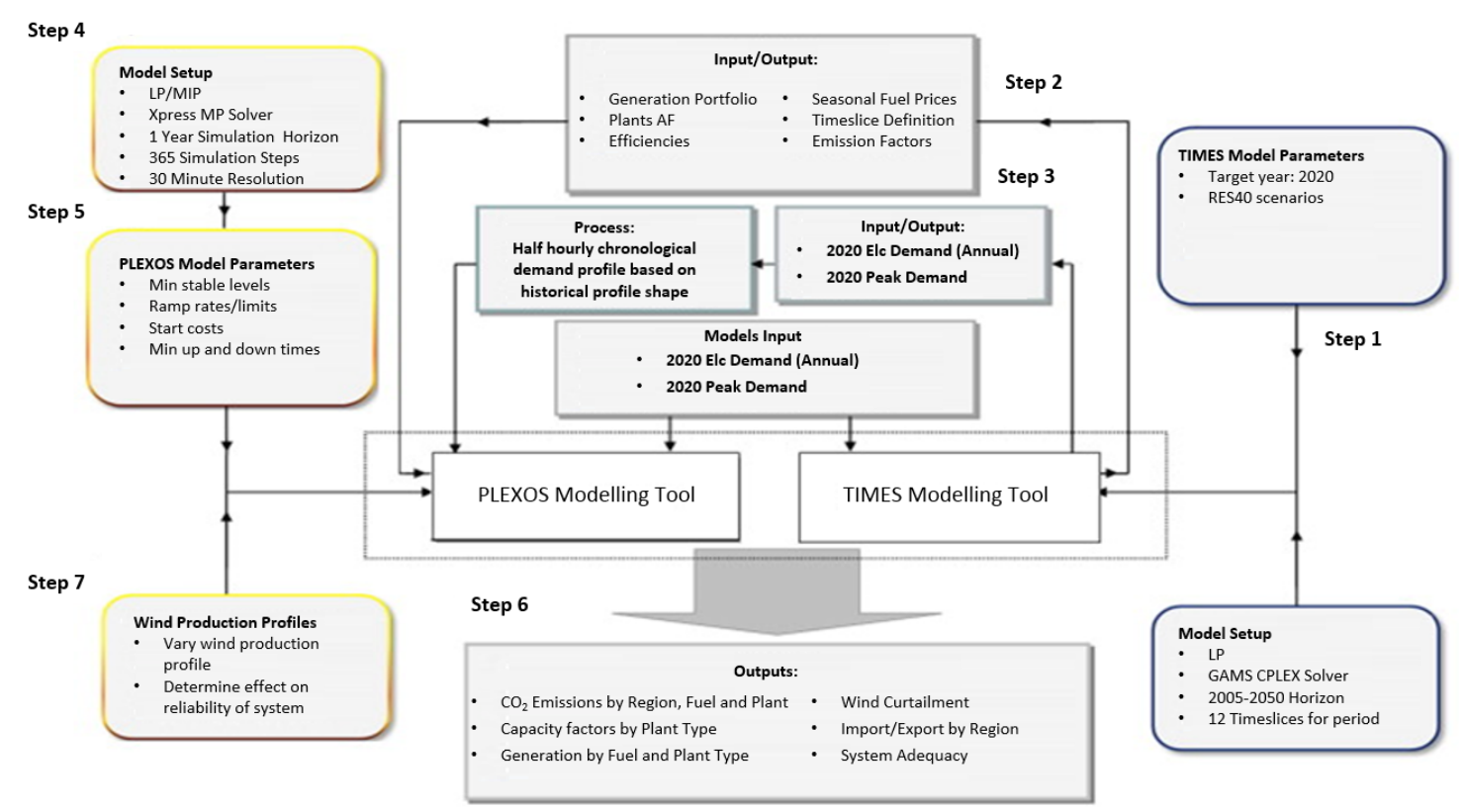

Figure 2 -Flow chart of soft-linking methodology. [11]

The main difficulty with bi-directional soft-linking is specifying the adaptation of parameters and/or constraints of the ESOM/IAM in response to the results provided by the UCED model in such a way that both models converge to a globally optimal solution. In [67], a bi-directional soft-link is used, but no information is provided on the details of the feedback from the UCED model to the ESOM. As stated in [68], this feedback mechanism is often ignored. In [14], maximum investment in wind generation capacity is restricted if annual curtailment of wind generation exceeds $10 \%$ of the expected annual wind generation. This feedback loop thus only directly impacts wind generation capacities. Sub-optimalities in the thermal generation fleet resulting from using a low level of temporal and technical detail are not corrected for. Hence, while this approach might result in a solution closer to the global optimum, this cannot be guaranteed. Further research is required to investigate the convergence in bi-directional soft-linking of ESOMs/IAMs and UCED models.

Soft-linking methodologies have recently been applied frequently to ESOMs. A number of studies used a uni-directional soft-link to analyse the impact of the limited level of temporal and technical detail typically used in ESOMs [10, 19, 69]. In addition, this approach has been applied in a number of studies to scrutinise energy system model results [67, 70, 71]. In [71], a soft-link between a MARKAL model of the Netherlands and REPOWERS is used to assess flexibility sufficiency, quantify the impact of part-load efficiency losses and assess the profitability of power plants in scenarios for the evolution of the Dutch power system. A similar analysis is performed in [70], where a soft-link between the ESOM MONET and PLEXOS is used to scrutinise the evolution of the Italian power system in different scenarios, with a focus on power system security. Rosen et al. [67] use a bidirectional soft link between the PERSEUS-CERT model and the AEOLIUS model to obtain more accurate estimates of displacement of intermediate-load and base-load plants by wind generation and the resulting impact on greenhouse gas emission reduction in Germany.

Recently, Zeyringer et al. [21] used a soft-link between an ESOM and a power system model with a high level of temporal and geographical detail. In contrast to the soft-linking approaches between 
ESOMs and UCED models, the power system model endogenously optimizes the location of the VRES and the need for conventional dispatchable technologies and storage technologies. This type of softlink has the benefit that it allows the provision of a solution which is closer to the global optimal solution without requiring a bi-directional soft-link.

While the soft-linking methodology can theoretically be applied to IAMs as well, the increased complexity due to a large number of regions and long time horizon covered make this a challenging exercise, as each power sector in each region and time step needs to be checked by a power system model run. Thus, the only examples we know of are a country-level IAM, namely the US-REGEN model that soft-links a CGE model of the United States to a bottom-up unit commitment and dispatch model [72], and a study with the global POLES model that soft-linked only the EU countries to a dispatch model based on 12 representative days [73].

\section{Advantages and Limitations}

The main advantage of soft-linking ESOMs/IAMs to UCED models is that it provides very detailed information on the operation of the power system. As such, this approach not only provides accurate estimates of the cost, fuel consumption and GHG emissions of operating the power system but also allows to analyse power system reliability, the need and provision of flexibility and the role specific generation technologies play in balancing demand and supply. As such, this methodology provides a robust check on the results provided by the ESOM/IAM. Using a bi-directional soft-link provides the additional advantage of improving the overall solution of the ESOM/IAM without requiring the computational resources needed to solve one ESOM/IAM with very high levels of temporal, technical and operational detail.

A first disadvantage is that two separate models need to be constructed and maintained, requiring additional resources and expertise. An additional disadvantage is that uni-directional soft-linking methodologies do not impact the investment decisions of the ESOM/IAM, and thus do not provide a globally optimal solution. In contrast, investment decisions can be altered in bi-directional softlinking methodologies. However, the feedback from the UCED model to the ESOM/IAM model is currently based on the skill and judgment of the modeller given the undertaking at hand. A limitation of this approach is that it is not a directly integrated approach, which makes it a sub-optimal approach because insights gained from the power system model have to be exogenously forced within the energy system model. More research is needed to investigate the convergence and the optimality of results provided by bi-directional soft-linking methodologies.

\subsection{Direct integration methodologies for ESOMs}

\subsubsection{Improving the temporal representation}

As discussed in Section 2.4, ESOMs typically have a stylized temporal representation, in which intraannual variations in demand and supply are represented by a low number of so-called time-slices. Haydt et al in [12] distinguish between two methods of balancing supply and demand in ESOMs.

A first method is the so-called 'integral method', in which typically 5-10 time-slices are used to distinguish between different load levels occurring throughout the year. In this method, each time 
slice thus represents an average load level during a certain fraction of the year. In this method, all chronological information is lost as different load levels can occur at different moments in time. Due to the loss of chronology, average VRES capacity factors are used. In addition, the dynamics of variations in demand and supply are not captured. As a result, the value of storage systems and other flexibility options cannot be determined.

A second method is the so-called 'semi-dynamic method' which is based on using a number of typical or representative days. In this 'semi-dynamic method' method, each typical or representative day represents a fraction of the year, e.g., corresponding to (a part of) a season. Each day can, in turn, be disaggregated into a number of diurnal time-slices. Due to the fact that chronology is retained within each day, the value of storage systems and other sources of flexibility can be endogenously determined. An example of a time-slice division disaggregating a year into seasonal, daily and diurnal time-slices is presented in Figure 3 [74]. At the lower level, each time-slice is defined by a fraction of the year it represents and a fixed value for the load and VRES capacity factors [10].

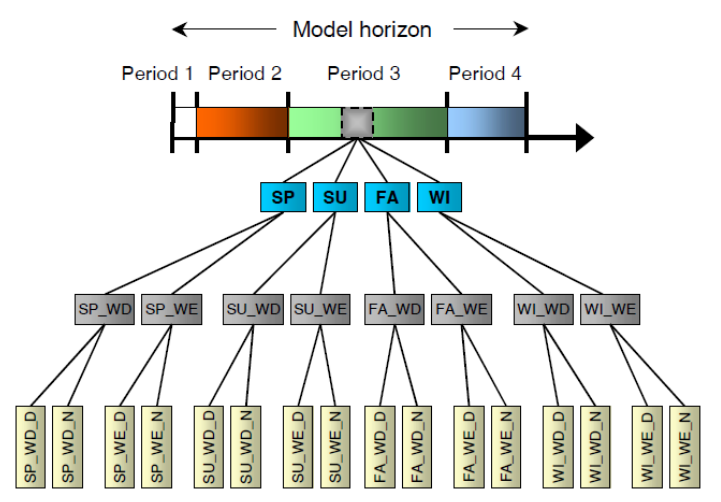

Figure 3: Example of a time-slice division used in energy system optimization models [74]

Recent literature has shown that the approach used to assign values for the load and VRES capacity factors to every time-slice can strongly impact the results [10]. The approach traditionally applied is to take the average value of that part of the time series that corresponds to the definition of the time-slice (e.g., the average solar capacity factor during summer days). A second approach only uses the data of a selected number of representative historical periods. These periods can in principle be hours (e.g., [72]), days (e.g., [75, 76]), or weeks (e.g., [16]). However, most commonly, a set of days is used.

In literature, the terms 'representative days', 'typical days' and 'type-days' are used interchangeably. All these terms are used to refer to both time-slice divisions based on using the data of a small selection of historical days, and to time slice divisions using the traditional approach where data averaging is used to obtain a number of typical days. In this text, we will refer to 'typical days' as days formed by averaging data, whereas we refer to 'representative days' as specific historical days.

In the majority of ESOMs, the semi-dynamic method of balancing demand and supply is used where data averaging is used to create a number of typical days. In this regard, a frequently occurring timeslice division uses 12 time-slices to distinguish between day, night and peak hours for four seasons, i.e., a single typical day is created per seasons which is further disaggregated into 3 diurnal time- 
slices. Examples of models using this time-slice division are the Irish TIMES model [65] and the JRCEU-TIMES model [66].

The impact of such a commonly applied, stylized, temporal representation on the model results has been investigated in great detail by multiple authors $[10-13,15,16,77]$. The results of their analyses have shown that using time-slices based on simple averaging leads to an underestimation of the variability of variable RES. This underestimation of the variability follows from the fact that when typical days are derived from a strictly temporal pattern (each time-slice represents a certain season, week, part of the day), the capacity factor assigned to each time-slice results from taking the average over each instance of the pattern. As VRES and specifically wind generation does usually not follow the same temporal pattern, the averaging thus smooths periods of very high and very low VRES generation. $[10,13,16]$. This, in turn, leads to an overestimation of the potential uptake of variable RES and an overestimation of the potential of baseload technologies while flexible and peak-load technologies are not sufficiently valued $[14,69]$. As a result, such a stylized temporal representation is shown to lead to an underestimation of the total system costs. While the impact on model results has shown to be limited to a low penetration of variable RES, it grows with penetrations of variable RES [10]. In the following, we present four methodologies to directly improve the temporal representation in ESOMs

\subsubsection{Semi-dynamic balancing using typical days with increased resolution}

First, a number of authors have experimented with increasing the temporal resolution (i.e., the number of diurnal time-slices) of the typical days [10, 12, 13, 15, 77-79]. Pina et al. [77] increase the number of time-slices used in a TIMES model for Sao Miguel (Azores, Portugal) to 288 by considering 4 seasons, 3 types of day per season (weekday, Saturday, Sunday) and 24 hours per day. By varying the number of diurnal time-slices, they show that using an hourly resolution impacts results. More specifically, fewer investments in wind turbines are observed when the resolution is increased. In an analysis of the Swiss power system using the Swiss TIMES electricity model (STEM -E) [79], the benefits of a greater temporal resolution are demonstrated by a comparison between the model with 288 time-slices and an aggregated version with 8 time-slices [78]. While increasing the temporal resolution is shown to yield some benefits, mainly in capturing the variations in load and solar generation, Ludig et. al. [13] have shown that increasing the resolution of the typical days is not sufficient to grasp the inherent variability of wind power, because wind generation in the studied area (Germany) is little correlated with the time of the day. A more elaborate discussion in this regard can be found in [10] where it is shown that it is not merely the temporal resolution which impacts results.

\subsubsection{Integral balancing based on approximating the joint probability distribution of the load and VRES generation}

A second methodology is to expand the integral method of balancing demand and supply to slicing the joint probability distribution of load and VRES generation. This can be done by not only distinguishing explicitly between different load levels occurring throughout a year but by simultaneously accounting for different levels of VRES generation $[10,73,80]$. Following the methodology of the integral method, a year can first be subdivided into different bands of load levels, each representing a certain fraction of the year. These time-slices can be further disaggregated into periods with high and low wind generation and high and low solar generation. The advantage of this approach is that the variability of load and VRES generation and their 
correlation are accounted for with only a limited number of time-slices. However, the disadvantage of this approach is that the chronology is lost, and the dynamics of the system and the corresponding value of flexibility options, such as storage systems, cannot be represented [10]. The importance of retaining chronology for the cost-optimal evolution of the South-Australian power system is analysed in [18], where the results of a model with and without chronology were compared. In the presented case, differences in the capacity mix were shown to be significant. The model that retains chronology is shown to invest less in VRES and baseload technologies and more in flexible thermal power plants. However, the total system cost resulting from the capacity expansion plans obtained using the model with and without chronology were shown to be very similar for the presented case. Recently, this improved integral method has been applied to the GET model [80].

\subsubsection{Semi-dynamic balancing using representative historical periods}

A final methodology is to use the semi-dynamic method with representative historical periods instead of averaged typical days. A schematic of using a set of historical periods in ESOMs is presented in Figure 4. From various time series (e.g., load, wind speed, solar irradiance), a number of representative periods $d \in D^{\prime}$ are selected. Each of these selected periods is given a certain weight $w_{d}$, i.e., the number of times this period is assumed to be repeated within a single year. The ESOM aims to minimize the sum of fixed costs and variable costs. While the fixed costs are only dependent on the investment decisions $\mathrm{cap}_{g}$ in different technologies $g$, the variable costs are dependent on the electricity generated by each of these technologies in every time step gen $n_{g, d, t}$. The balance of demand and supply is imposed for every time step $t$ (e.g., hour) of every representative period $d$. The weights $w_{d}$ are then used to scale the variable costs incurred during each representative period to an equivalent annual amount. Similarly, the annual electricity generation from different generation technologies $g$ and the corresponding greenhouse gasses can be scaled to equivalent annual amounts. Since only the data of historical periods is used, averaging of load or VRES generation is only needed to reduce the number of diurnal time-slices. As a result, the variability of load levels and VRES generation can be captured. In addition, chronology is maintained. For these reasons, this methodology can capture the short-term dynamic variations in demand and supply, which is crucial to assess the value of and need for short-term storage systems, and to allow modelling the limited flexibility of the generation technologies (e.g., ramping rates, start-up costs). However, a careful selection of a set of representative historical periods is essential for the quality of this methodology. Indeed, not every set of historical periods will provide a good approximation of the joint probability distribution of load and VRES generation levels, as shown in [10]. Therefore, care should be taken in carefully selecting a representative set of historical periods. 
Input time series

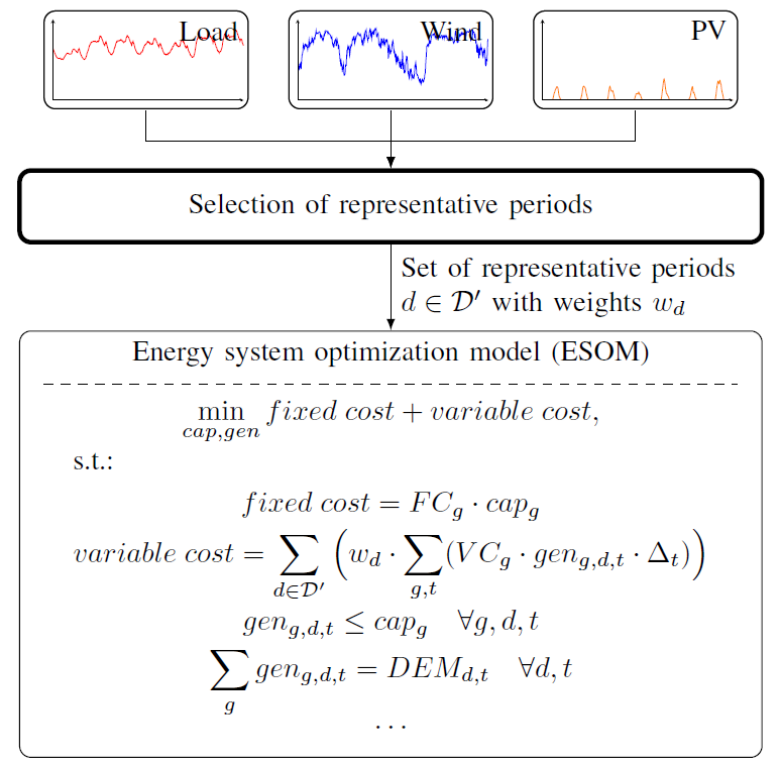

Figure 4: Schematic of how a set of representative days can be used in ESOMs [76]

To select a representative set of historical periods, multiple approaches can be found in the literature. A comprehensive overview of different approaches, their strengths and limitations can be found in [76]. Certain approaches rely on simple heuristics (e.g.[81-85]). More advanced approaches make use of clustering algorithms to cluster days with similar load, wind speed and solar irradiance patterns. Different clustering algorithms, such as Ward's hierarchical clustering algorithm [75], the kmedoids [86], k-means [87-89] and fuzzy C-means algorithm [86] have been applied in this regard. Once all days are grouped into a number of clusters, a single representative day is selected from each cluster. The weight assigned to each representative day, i.e., the number of time this representative days is assumed to be repeated within one year, corresponds to the number of days that are grouped into its parent cluster. These clustering algorithms thus have the advantage that the weights of each representative day are determined exogenously. This allows to account for rare events, while common situations can be represented by a low number of days with large weights. Clustering techniques have been applied to select representative periods in the LIMES-EU model [90], the US-REGEN model [72] and the POTEnCIA model [91]. Other approaches randomly select numerous potential sets of representative historical periods and use metrics to assess the quality of these sets in order to pick a representative set of historical periods [16]. A fundamental difference with the heuristic approaches discussed above is that the selection is based on the evaluation of the full set of representative periods, whereas in the heuristic approaches, the selection is based on the characteristics of individual historical periods or the similarity between individual historical periods. A final approach makes use of a mixed-integer linear programming (MILP) model to select a set of representative historical days (binary variables) and their weights (linear variables) in order to minimize the errors in approximating the distribution of load and VRES generation time series as well as their correlation [76].

Different approaches to select representative days are compared in [76]. It is shown that by optimizing the selection and weights of the representative days using the MILP model, more accurate results are obtained than the ones obtained through random selection algorithms, 
clustering algorithms and heuristic approaches. A better selection of representative days allows to increase the accuracy from the ESOM without increasing the computational cost. Particularly for models which are restricted to a low number of time-slices, the added value of a better selection of representative days can be high.

In an application of the LIMES-EU model of the European power system, Nahmmacher et al. [75] have compared the model results for a varying number of representative days. Their results show that the accuracy of the ESOM increases as more representative days are selected, but the marginal benefit of increasing the number of days rapidly decreases. As a trade-off needs to be made between the computational complexity and the accuracy of the model, they conclude that using 6 representative days is sufficient to obtain a reasonable accuracy: in their presented case, increasing the resolution from 6 to 100 representative days only changes total system costs by $4 \%$. Using a 3hourly time-resolution, the 6 representative days corresponds to a total of 48 time-slices, which lies in the range of time-slices frequently used in ESOMs.

\subsubsection{Using stochastic programming as a means to address modelling uncertainties}

Increasing the temporal representation to capture RES profiles improves the quality of the solution obtained, and by using state-of-the-art methodologies for selecting representative days leads to accurate sampling of solar and wind availability historical profiles and results in investment decisions that incorporate notions of hedging. Yet, these investment decisions are taken with perfect knowledge about the availability of solar and wind energy, while in reality they are made before the uncertainty surrounding this availability is resolved. This decision problem can be accurately modelled with a two-stage stochastic programming [92] which can be applied in a similar manner as it has been applied for long-term decisions under uncertainty, e.g. in [93-95]. Thus, the investments in power generation and storage technologies can be made in the first stage, while in the second stage these investment decisions are fixed, the uncertainty about the solar/wind profiles is resolved and recourse actions are taken to find optimal investment decisions. The application of stochastic programming relies on scenario trees, in which each stage corresponds to a resolution time ${ }^{3}$ and is characterised by a set of states ${ }^{4}$ (Figure 5 on the left). Each path from the first node to any last node in the tree is called "scenario". A typical mathematical formulation of a two-stage stochastic programming problem can be found in [96].

Recurring uncertainties, such as hydrological and wind/solar conditions, lead to a simplified formulation, because the information about already resolved uncertainties of the past cannot be used for future investment decisions [97]. Thus, the investment decisions variables have a single state in all periods, and only period-specific generation variables are split into the set of states implied by the scenario tree. If the recurring uncertainties can be also considered independent between successive periods ${ }^{5}$, then a further simplification can be achieved by taking into account that the impacts these uncertainties are no longer conditional on the state of the previous period. This assumption eliminates the necessity to branch the scenario tree in every modelling time period (Figure 5 on the right). Following this approach, the investment decisions are made in the first stage for every modelled time period and come into effect in the second stage of the same modelled period, by when the true availability of wind and solar energy is revealed [98].

\footnotetext{
${ }^{3}$ Resolution time is the time when the actual value of the uncertain parameter is revealed.

${ }^{4}$ The states correspond to the different values, together with their corresponding probabilities, that an uncertain parameter has in this particular stage.

${ }^{5}$ This holds for example in the uncertainties related to solar and wind availability.
} 
Each node of the second stage in the scenario tree has an operational time structure, defined by a number of timeslices (in Figure 5288 timeslices are defined in each node delineated into 4 seasons and 3 typical days of hourly resolution). Solar and wind profiles are mapped to these timeslices either by random sampling or by using representative days (see section 3.2.1.3). All nodes belonging to the same scenario have exactly the same wind and solar profiles. However, across different scenarios the solar and wind profiles are different and they are associated with a probability of occurrence ${ }^{6}$. The total number of timeslices in a modelling year is the product of scenarios with the number of timeslices in each node ${ }^{7}$.

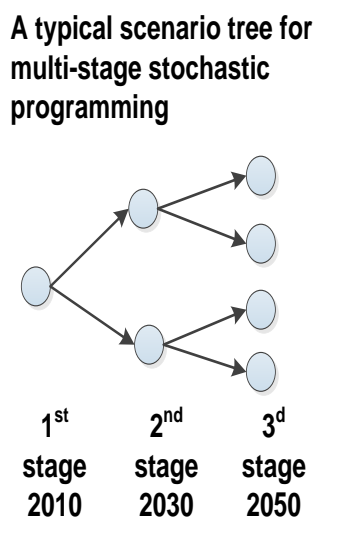

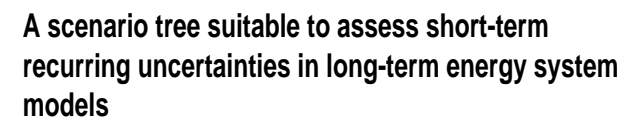
models

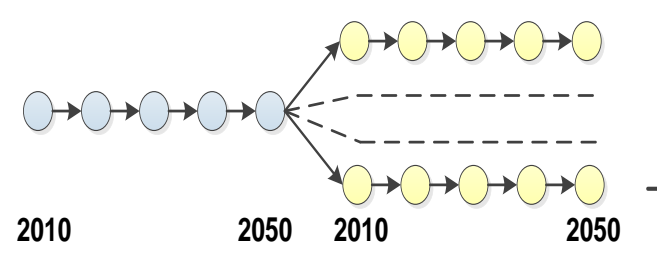

Stage 1: investment decisions
Stage 2: operational decisions

In each node of Stage 2 there is
a representation of operational
time structure
\begin{tabular}{|c|c|}
\hline WIN-WK-H01 .... WIN-WK-H24 \\
\hline WIN-SA-H01 .... WIN-SA-H24 \\
\hline WIN-SU-H01 .... WIN-SU-H24 \\
\hline SPR-WK-H01 ...SPR-WK-H24 \\
\hline SPR-SA-H01 ... SPR-SA-H24 \\
\hline SPR-SU-H01 ... SPR-SU-H24 \\
\hline SUM-WK-H01 ... SUM-WK-H24 \\
\hline SUM-SA-H01 ... SUM-SA-H24 \\
\hline SUM-SU-H01 ... SUM-SU-H24 \\
\hline FAL-WK-H01 .... FAL-WK-H24 \\
\hline FAL-SA-H01 .... FAL-SA-H24 \\
\hline FAL-SU-H01 .... FAL-SU-H24 \\
\hline
\end{tabular}

Figure 5: On the left a multi-stage scenario tree; On the right: a modified scenario tree for recurring independent between successive periods short-term uncertainties.

The derived scenario tree must be stable in order to ensure that the solution obtained does not depend on the representation of the scenario tree but on the underlying data set. This requires a large number of scenarios to be initially created by using appropriate scenario tree generation algorithms $[99,100]$ and then to employ scenario reduction techniques [101] to improve the computational time. For example, iterative random sampling of actual historical days can be employed ${ }^{8}[98]$ in order to create a large number of different scenario trees and then to select the one that displays the minimum deviation in the first four moments ${ }^{9}$ with the historical data. Alternatively one may consider the application of state-of-the-art methodologies for selecting representative days (section 3.2.1.3) to generate different scenarios that correspond for example to different historical years.

Among the advantages of using stochastic programming are: a) the evaluation of hedging strategies; b) the endogenous requirements of back-up capacity; c) the possibility to measure the expected system cost disregarding uncertainty through the metric of the Value of Stochastic Solution ${ }^{10}$ (VSS) [102, 103], and; d) the provision of insights regarding the additional cost for providing back-up

\footnotetext{
${ }^{6}$ This also implies that there is the flexibility to use state-of-the-art methodologies for selecting representative days for each scenario in the scenario tree and then each scenario to correspond to wind and solar profiles from different historical years.

${ }^{7}$ For example if we assume 90 scenarios with 288 timeslices in each node, then the total number of timeslices in a year is 25920; this implies that a typical operational hour in a year is delineated into several instances with respect to the values of the underlying random variables.

${ }^{8}$ For example $S$ days are randomly selected to form the nodes of a scenario tree and by repeating this sampling $N$ times, $N$ different scenario trees are constructed from which the one that better reflects the underlying probability distributions of the random variables is selected.

${ }^{9}$ The first four moments of a probability distribution include: mean, variance, skewness and kurtosis.

${ }^{10}$ The VSS is defined as the difference between the expected optimal objective function value of the stochastic model with fixed investment decisions as they calculated by the deterministic model and the value of the objective function from the stochastic model.
} 
capacity and storage options ${ }^{11}$ (and also for diversifying the electricity generation mix) through other metrics [102] and especially through the Expected Value of Perfect Information ${ }^{12}$ (EVPI) .

In concluding this section, it should be noted that the approach presented in section 3.2.1.3 can be used in stochastic programming to improve the sampling of the underlying distributions of wind and solar power. This synergy occurs when constructing a specific scenario in the scenario tree. In fact, the similarity of stochastic programming and the approach presented in section 3.2.1.3 is that both are sampling the distributions of solar and wind availability with high accuracy. The difference lies that in deterministic approaches the investments are made with perfect knowledge about the solar and wind availability, while in stochastic programming this information is unknown at the time of the investment.

\section{Advantages and Limitations}

Four distinct methodologies have been put forward in literature. The first methodology to improve the temporal representation in ESOMs that has been described above is to increase the resolution of the typical days. Due to the fact that typical days are created by averaging data of multiple days, the variability of VRES capacity factors is underestimated, even if the resolution is increased.

A second methodology is to expand the integral method of balancing demand and supply to approximate the joint probability distribution of load and VRES generation. The first advantage of this approach is that the distribution of the load and VRES generation can be captured relatively well in a limited number of time-slices. Second, the correlation between different time series is accounted for. This way, the RLDC will be approximated well for varying shares of VRES. Finally, implementing this approach requires a minimal effort. However, the main drawback of this approach is that chronology is lost, making it impossible to endogenously incorporate technical dynamic constraints and to determine the value of storage and other flexibility options.

Another methodology is to use the data of a limited number of representative historical periods. The advantage of this approach is that both the distribution of the load and VRES generation can be captured while at the same time retaining the chronology. The main disadvantage of this approach is that the quality of this approach is strongly dependent on a good selection of a representative set of historical periods. A proper selection of a representative set of historical periods, therefore, requires the implementation of specific selection algorithms or optimization routines.

The stochastic programming based methodology has benefits in that it makes the need for back-up capacity endogenous, allows for the hedging of flexible generation and allows for detailed quantification of uncertainty. Limitations of the approach are its dependence on the representation of uncertainty parameters which are specific and influential in model results and that the approach adds to the computation cost required for the model run ${ }^{13}$

\footnotetext{
${ }^{11}$ This can be also viewed as the support for enabling investment in flexible technologies (e.g. capacity payments) and in storage options to cope with the intermittency of solar and wind power.

${ }^{12}$ The EVPI is the difference between the average performance with perfect information and the optimal stochastic solution. The EVPI can be also used as a proxy of how much are willing to pay to eliminate uncertainty.

${ }^{13}$ Solving a recourse problem is generally difficult because it requires the evaluation of the expected costs of the second stage. This implies a high-dimensional numerical integration on the solutions to the individual
} 
All these methodologies aim to improve the temporal representation such that the operations of the power system and the resulting cost, fuel consumption, GHG emissions, and reliability are better approximated. As such, by improving the temporal representation directly in the ESOM, the solution will become closer to the global optimal solution. While these approaches can be used to provide a more adequate and reliable power system, using either of these approaches is not sufficient to guarantee a reliable system. To this end, an even higher level of temporal detail and the inclusion of technical constraints would be required, as is the case in the soft-linking methodology. Moreover, all three methodologies highlighted above require using a somewhat higher number of time-slices than most ESOMs use at this moment.

\subsubsection{Improving the technical representation}

As discussed in Section 2.4, ESOMs typically do not consider individual power plants and the corresponding load-following constraints. This leads to an underestimation of total system cost and the need for flexibility providers $[10,11,19,20,104]$. Although the impact of reduced technical detail is significant, for high penetration levels of VRES, it was shown that the impact of the stylized temporal representation typically used in ESOMs is higher than the impact of the level of technical detail $[11,104]$.

\subsubsection{Stylized integration of operational constraints}

A detailed implementation of the technical constraints which limit the flexibility of dispatchable power plants requires considering individual units and use of chronological data with a sufficiently high resolution [10]. As using such a high level of detail would make ESOMs intractable, more stylized representations of technical constraints are frequently implemented. As such, these stylized constraints do not directly represent the physical processes, but rather aim to mimic the impact of these physical constraints on the generation scheduling. Therefore, calibration of such constraints using more detailed models is required. Moreover, as this calibration depends on a lot of parameters, care is needed in transferring these constraints to applications of different power systems.

There are ample examples of such stylized representations of technical constraints. A first example can be found in [105], where a must-run level and ramping rates are specified at a technology level to represent all technical constraints and costs related to load-following. For this reason, they state that the applied ramping rates should not be directly compared to the ramping rates of individual power plants. The European Electricity Market Model (EMMA) also does not consider individual plants (and corresponding integer variables). To mimic the behaviour of plant operators with respect to start-ups, generation costs of certain technologies are lowered such that these plants would not shut down if electricity prices would briefly drop below the actual generation cost. To prevent distorting total costs, the fixed costs of these technologies are increased [106]. Although this approach can to some extent mimic the effect of start-up costs, it does not allow modelling of hard physical constraints such as maximal ramping rates and minimum up and down times. Similarly, in the Regional Energy Deployment System (ReEDS), a cost penalty is attached to ramping and a

mathematical programs of the second stage. However, when the random data are discreetly distributed then the stochastic problem can be written as a deterministic equivalent problem, in which the expectations are included as finite sums and each constraint is duplicated for each realisation of the random variables. 
minimum loading constraints prevents certain technologies from excessive cycling [107]. One specific, very popular, though highly stylized, method frequently used is to differentiate between inflexible (baseload) plants and flexible (peakload) plants by defining them at a different time slice levels. Typically, nuclear plants are defined at the annual level, meaning that their output is assumed to be fixed at one level for the entire year. Coal plants are often assumed to be slightly more flexible so that they can change their output between different seasonal time slices, while more flexible technologies are allowed to adapt power output freely. Although the exact implementation can differ, this method is amongst others used in [15, 66, 84, 108]. Recent developments of modelling frameworks for ESOMs enable stylized capture of the Unit Commitment and Economic Dispatch (with representation of characteristics such as ramping, minimum stable operation levels, minimum up and down times, start up and shutdown times and partial load efficiencies), such as for the TIMES ESOM in [109].

\subsubsection{Modelling ancillary services markets in long-term energy system models}

Ancillary services (or operating reserves) are provided by power plants in order to balance the power system in the case of forecast errors in supply and demand that result in frequency deviations. Three types of operating reserves are typically distinguished with different activation times [110]: primary, secondary and tertiary. A number of studies have already shown that inclusion of the need for operating reserves can have a significant impact on the results obtained from power system models $[17,19,20]$ and this provides an argument for implementing them also in ESOMs. Because in ESOMs a technology is usually assumed to comprise an indefinite number of power plants ${ }^{14}$, a stylized approach has to be followed [111], in which the technologies compete in both wholesale electricity and ancillary services markets. A technology can be logically divided into two parts: the part $p$ participates in the electricity market, while the part $p p$ participates in the ancillary services markets (Figure 6). A capacity transfer equation ensures that there is sufficient capacity for both electricity generation and provision of positive reserves. On the other hand, negative reserves can be implemented as constraints on the minimum electricity generation requirements. The trade-off between committing capacity to the electricity market versus grid balancing is based on the marginal cost of electricity production (in order to cover generation costs) and the marginal cost of capacity in the reserve market (which accounts as a revenue in order to cover fixed operating and investment costs).

The analyst may define also a maximum share of online capacity of each technology, according to which a technology can contribute to meeting negative reserves. The provision of positive reserves may not be dependent on the online capacities, since some technologies can ramp-up fast enough to provide positive reserve without the need for any plants to be online.

\footnotetext{
${ }^{14}$ Otherwise mixed integer programming can be employed to identify concrete power plant block sizes.
} 


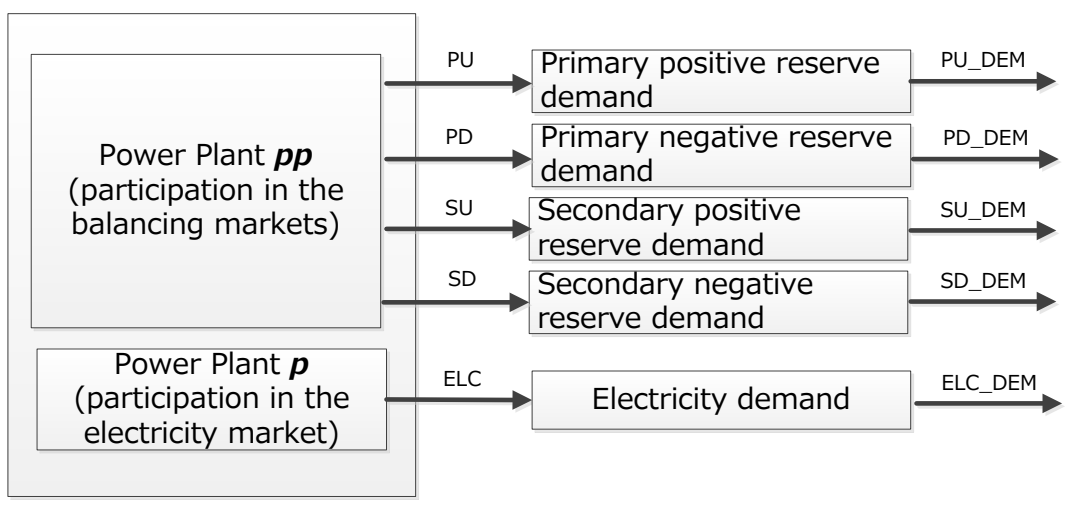

Figure 6: A stylized approach for introducing ancillary markets in ESOMs.

Following the approach presented in [68] a power plant can be classified into one of the following three categories with respect to the provision of primary and secondary reserve, given that the analyst has specified the time horizon associated with each reserve type:

- Flexible technologies with high ramping rates, which can bring additional online capacity (or withdraw capacity) within the specified reserve timeframe to meet the reserve demand. The provision of positive reserve is constrained by the total available capacity, while the provision of negative reserve can be equal to the electricity generation capacity. Thus, there is no need to keep more capacity online than what is needed for electricity generation.

- Non-flexible units with low ramping rates, which can provide limited negative reserve (constrained by the ramping rates), which is not more than the difference between the current generation level and the minimum stable operation, and limited positive reserve (constrained by the ramping rates), which is not more than the difference between the maximum available capacity and the capacity committed for electricity generation). Thus, the capacity committed for electricity generation should exceed the minimum stable operation level and the provided negative reserves, while the total online capacity should be equal to the capacity committed for electricity generation plus all provided positive reserves.

- Technologies which cannot provide fast enough primary reserve but are suitable for secondary reserve. This implies a combination of the above two categories: the provision of primary reserve requires an operation below the online capacity in order to ramp-up the generation if needed; the secondary reserve is constrained by the ramping characteristics and the total available capacity of a technology. The required minimum electricity generation has to be at least as high as the secondary negative reserve provided. Any additional primary negative reserve requires an operation above the minimum stable operation level

The demand for operating reserves can be determined endogenously by using a probabilistic approach [112] (see also Figure 7). First, the individual probability density functions (PDF) of the random variables regarding the forecast errors in electricity demand, in wind production and in solar production are estimated, either from historical data or theoretical considerations ${ }^{15}$. Then the joint density distribution is derived by means of statistical convolution. Additional random variables, e.g.

${ }^{15}$ The most common approach is to assume a Gaussian distribution of the forecast error with mean 0 and standard error equal to the forecast error [113] Doherty R, O'Malley M. A new approach to quantify reserve demand in systems with significant installed wind capacity. IEEE Transactions on Power Systems. 2005;20:58795, [114] Ortega-Vazquez MA, Kirschen DS. Estimating the spinning reserve requirements in systems with significant wind power generation penetration. Ibid. 2009;24:114-24. or a hyperbolic distribution[115] Hodge B-M, Florita A, Orwig K, Lew D, Milligan M. A comparison of wind power and load forecasting error distributions. 2012 World Renewable Energy Forum2012. p. 13-7. 
plant outages, can also be included provided that there is an underlying probability density function that describes them. Finally, positive and negative reserves are set in a way that the area under the density function equals three standard deviations ${ }^{16}$ [113]. For example, by assuming independence between demand, wind and solar forecast errors, the reserve requirements in hour $t$ are:

$$
R_{t}=3 * \sqrt{\sum_{k}\left(\sigma_{D, k}^{2} \cdot D_{k, t}^{2}\right)+\sum_{m}\left(\sigma_{S, m}^{2} \cdot S_{m, t}^{2}\right)}
$$

where $D_{k, t}$ is the electricity demand of end-use sector $k, S_{m, t}$ is the electricity generation of the stochastic RES option $m, \sigma_{D, k}$ is the variance of the probability density function of the forecast error of electricity demand in sector $k, \sigma_{S, m}$ is the variance of the probability density function of the forecast error of electricity production from the stochastic renewable source $m$. Additional terms, e.g. the loss of the largest unit ( $\mathrm{N}-1$ criterion) can be also included in the above equation [112].

\section{Plant outages PV forecast errors Wind forecast errors Load forecast errors}
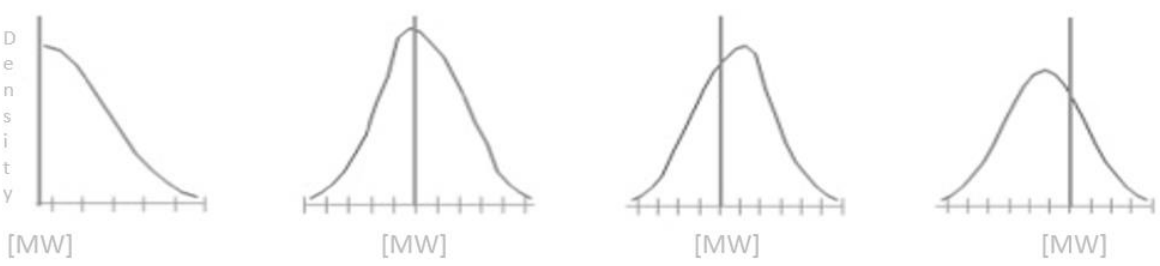

$[\mathrm{MW}]$

$[\mathrm{MW}]$

$[\mathrm{MW}]$

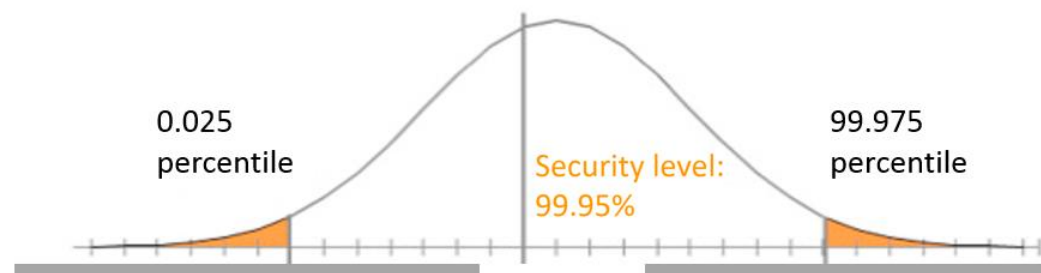

Neg. capacity requirements

Figure 7: A probabilistic approach for ex-ante determination of requiring positive and negative control capacity [112].

The above approach implies different standard deviations for the PDFs of demand, wind and solar forecast errors for the different operational reserve types (primary, secondary and tertiary). In [118] it is suggested that variations in wind production, solar production and demand over a half an hour time horizon to be chosen for estimating primary reserve requirements and over a four-hour horizon for secondary reserve requirements ${ }^{17}$.

\footnotetext{
${ }^{16}$ Since this is a non-linear equation, in LP models this expression has to be linearised, by applying techniques based on regression [116] Freedman DA. Statistical models: theory and practice: cambridge university press; 2009. or stochastic linearisation [117] Socha L. Linearization methods for stochastic dynamic systems: Springer Science \& Business Media; 2007. or simple linearisation.

${ }^{17}$ For example, by following this approach, standard deviations for demand wind and solar for primary reserve is $0.25 \%, 1.4 \%$ and $0.4 \%$ respectively in [111] Vögelin P, Georges G, Noembrini F, Koch B, Boulouchos K, Buffat $\mathrm{R}$, et al. System modelling for assessing the potential of decentralised biomass-CHP plants to stabilise the Swiss electricity network with increased fluctuating renewable generation. http://www.bfe.admin.ch/php/modules/enet/streamfile.php?file=000000011337.pdf 2016., while for secondary reserves is $1.3 \%, 6.0 \%$ and $5.9 \%$ in the same study. Similarly in [68] Welsch $M$, Howells $M$, Hesamzadeh MR, Ó Gallachóir B, Deane P, Strachan N, et al. Supporting security and adequacy in future energy systems: The need to enhance long-term energy system models to better treat issues related to variability.
} 
The stylized approach described above requires assumptions on the maximum share of online capacity of each technology that can contribute to negative reserve provision. In addition, the analyst may introduce minimum shares of positive primary and secondary reserve that has to be provided from online plants, in order to avoid unrealistic situations when all the positive reserve is provided by offline units. A key assumption, though, is the forecast errors in wind, solar and electricity load. Moreover, they are also needed assumptions about the evolution of the quality of the forecasting techniques in the long-term and to the extent that different technologies can contribute to these reserves [119]. Another consideration is that the forecast error depends on weather and geographical conditions, as well as on technology sites, that if aggregated can lead to a decrease in the spread of forecasting errors [120].

\section{Advantages and Limitations}

Two approaches have been described with the aim of directly improving the technical representation in ESOMs each with their respective advantages and limitations.

The stylized integration of operational constraints has a key benefit in that it allows easy integration of different operational constraints the model that directly increase the optimality of the solution. However, given they are stylized, they do not explicitly capture the system constraints - they mimic them. This means that the validity of such integrated constraints cannot always be guaranteed and they often require calibration through use of more detailed models.

The methodology that integrates the requirement ancillary services into the optimisation of the system adds value to modelling result in that it allows for the increased optimality of the solution and captures a very influential technical constraint on system operation that is often omitted from such long-term planning models. An obvious limitation is that it requires the use of additional variables and constraints that increase the computation complexity required for a solution. Another is the uncertainty surrounding the endogenous sizing of operating reserve requirement over long time horizons, which makes the integration of these requirements into ESOMs challenging given the technological developments that may alter required operational reserves in future. A final limitation is that it requires an assumption on the evolution of the accuracy of the forecasting techniques regarding wind, solar and electricity load profiles.

International Journal of Energy Research. 2015;39:377-96. the standard deviations of $1 \%$ and $1.4 \%$ were used for demand and the wind standard deviations respectively for assessing primary reserve requirements, while $2 \%$ and $6 \%$ for secondary reserves. 


\subsection{Direct integration methodologies for IAMs}

A very different approach to representing the integration challenges of wind and solar in large-scale energy-economy models (or IAMs) was developed by Ueckerdt et al [121, 122]: the residual load duration curve (RLDC) approach. IAMs are used to analyse long-term mitigation strategies, and are therefore very complex - they need to include all energy sectors and carriers, all world regions, and cover the full $21^{\text {st }}$ century. Adding hundreds of time-slices would increase the numerical complexity to a level that currently would make them unsolvable. In contrast to other approaches that substantially increase the temporal resolution of the energy modelling tool, the RLDC-approach is based on a pre-analysis of detailed temporal data about load and generation from variable renewable energies (VRE) in order to extract the important dynamics and only implements these in the IAM. It takes advantage of the fact that many of the fundamental properties of a power system are contained in the RLDC [123]. An RLDC is the temporally reordered residual load that needs to be supplied by dispatchable power plants at a given share of VRE in the electricity generation mix (see Figure 8). The RLDC contains i) the peak demand that needs to be met by dispatchable capacities, ii) the number of hours that a certain capacity level is needed, and iii) the curtailment in times when VRE supply is larger than load. Because the RLDC ignores the chronology of the year, the RLDC and thereby these characteristics of a power system can be described quite accurately with a relatively small number of parameters.

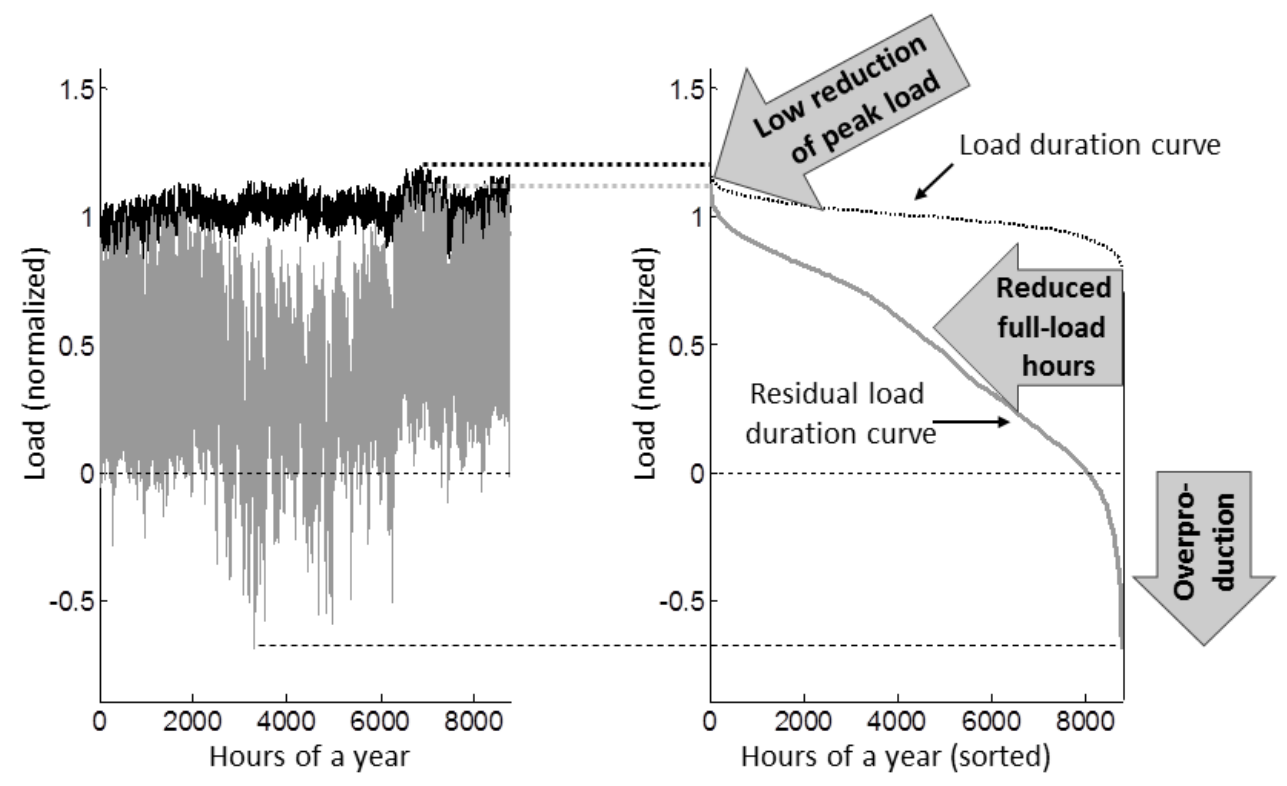

Figure 8: Chronological (left) and duration curves (right). The upper black line represents the load, while the lower grey line represents the residual load that needs to be covered by dispatchable power plants after adding $25 \%$ generation from wind and $25 \%$ generation from PV. To calculate the duration curves on the right, both load and residual load are reordered from highest to lowest value. The RLDC on the right shows three main challenges arising from including wind and solar: They do not fully contribute to the reduction of peak load, they lead to lower utilization of dispatchable power plants, and they can produce more than load, leading to curtailments. 
The RLDC approach as implemented in the integrated assessment model REMIND $[4,60,64]$ is based on a direct representation of the dynamic changes of the residual load duration curve with increasing wind and solar generation [122]. While the representative day approach presented in the following section uses a large number of time-slices to recreate the RLDC at various VRE shares, the RLDC approach uses only very few load bands to represent the shape of the RLDC but varies the height of each load band non-linearly depending on the share of wind and solar. Accordingly, the RLDC approach is only useful for non-linear models. The RLDC implementation in REMIND increased model runtimes by a factor 3-5.

In REMIND, the RLDC is represented through six values: four load bands representing the shape of the RLDC curve, a superpeak capacity requirement, and the amount of curtailment (see Figure 9). Each of these 6 values is represented by a third-order polynomial that depends on the relative contribution of PV and wind to load (see Figure 10 to see how the height of the superpeak decreases with increasing wind and solar share). The model ensures that sufficient dispatchable capacity is installed to cover each load band, and calculates the resulting capacity factors from the full load hours of a load band. For a more detailed description including a full parameterization for all world regions, see [122].
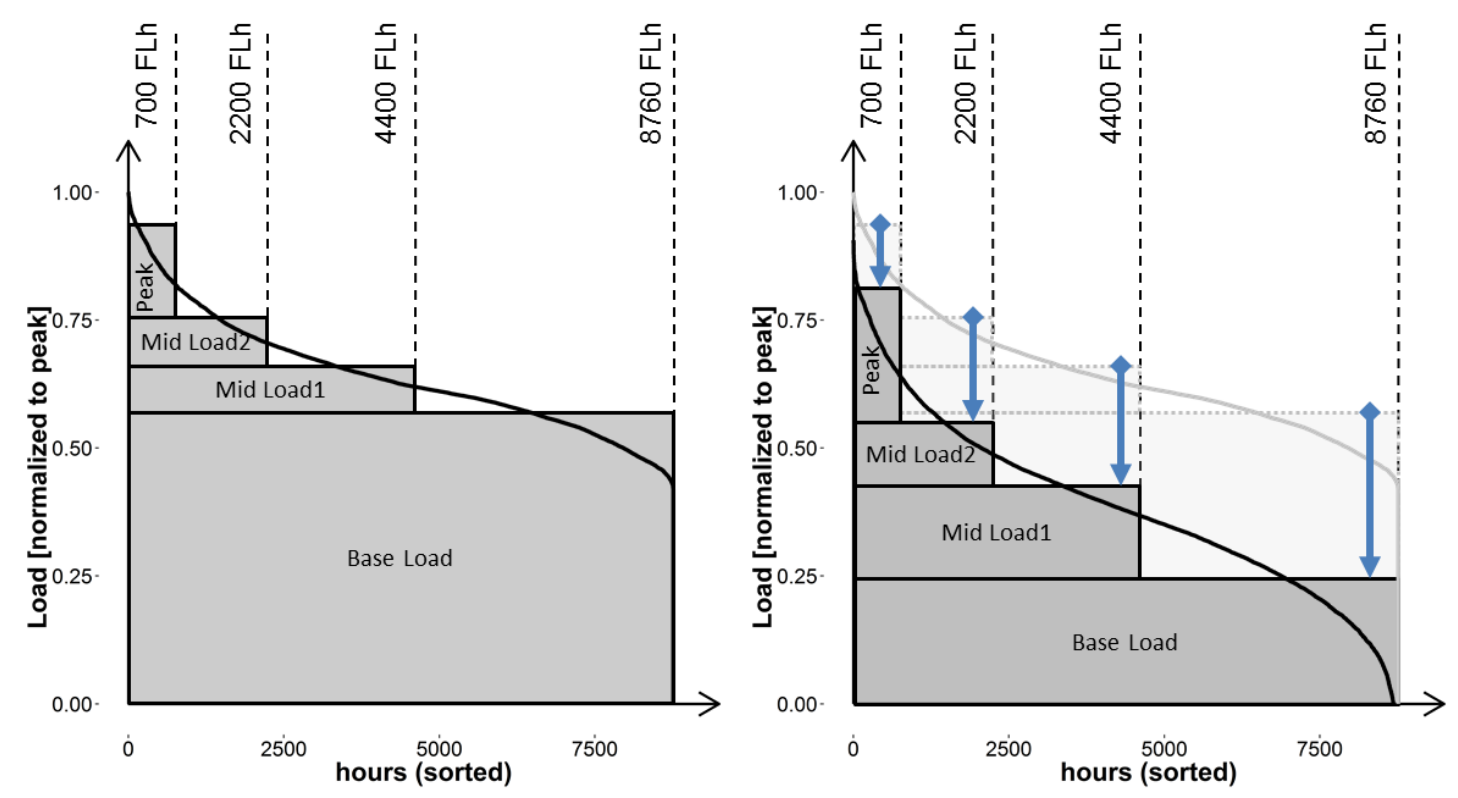

Figure 9: Left: Representation of RLDCs in REMIND in a discretized form with the help of four load bands. Left: Black line represents the RLDC at $0 \%$ VRE; the load band heights of the four load bands are fitted to best represent the RLDC. Right: At a wind share of $40 \%$, the RLDC is decreased (black curve). According to the changing slope of the RLDC, the reduction of load band heights (as shown by the blue arrows) is very different across the different load bands. The height of the base load band is reduced much stronger than the height of the mid and peak load bands.

The REMIND model intertemporally optimizes the investment into both VRE and dispatchable capacities to meet a price-elastic electricity demand. In climate mitigation scenarios, carbon prices increase the cost of conventional power plants, so that more wind and solar power is deployed. As wind and solar shares increase, the base load band shrinks in comparison to the mid and peak load bands (see Figure 9, right). Accordingly, the model will over time replace the current power system consisting of a large share of baseload plants and invest more into dispatchable power plants with low capital intensity, such as open-cycle gas turbines or hydrogen turbines. 


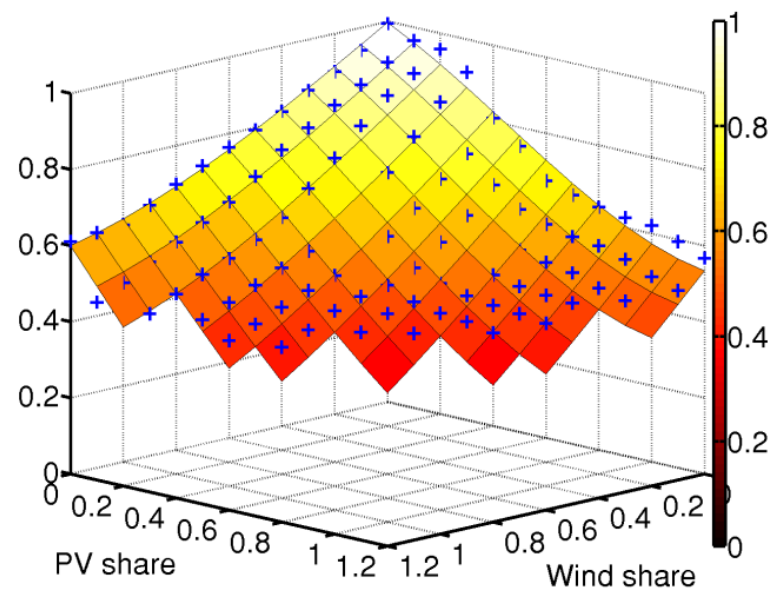

Figure 10: Change of the superpeak value ( $z$-axis) with increasing wind and solar share ( $x / y$-axes), assuming use of shortterm storage. The depicted values are normalized to the superpeak value in a system without wind or solar. Blue crosses represent individual DIMES model runs, the coloured surface represents the third order polynomial representation in REMIND. In $\mathrm{x} / \mathrm{y}$ direction, blue crosses sit at the crossing of black surface lines - if the crosses are fully visible, they have a value larger than the polynomial fit, if the crosses are clipped or hidden by the surface, they have a value lower than the polynomial fit.

While the REMIND full implementation of the RLDCs requires the use of non-linear solvers to represent the third-order polynomials, the MESSAGE model includes mixed-integer approximations of some of the key characteristics of the RLDC, such as the VRES-share-dependent contribution of wind and solar to covering peak demand, or VRES-share-dependent flexibility requirements [124].

As the RLDC contains no information on chronology, the use of short-term storage such as pumped hydro storage or battery storage is difficult to implement endogenously in this approach. The reason is that short-term storage technologies like batteries are relatively costly and have especially high reservoir costs, thus they are most competitive if times with overproduction and times with high demand alternate frequently - therefore, photovoltaics with its diurnal variation is a natural complement for short-term storage. However, an RLDC does not contain any information whether or not the times with high demand on the left side of the RLDC alternate with the hours of overproduction on the right-hand side of the RLDC.

To still include the effect of short-term storage in RLDC-based approaches, it is necessary to preprocess the RLDC data and derive some proxy for the periodicity of the residual load. For the RLDCs developed in [122], the one node full year hourly dispatch and investment model DIMES was used to calculate cost-optimal short-term storage deployment at different wind and solar shares on the basis of the load and generation time series with full hourly detail over the year. In a way, this process has similarities with the uni-directional soft-linking described in 3.1 but acts in the opposite direction: the highly detailed model is used to parameterize the inputs to the IAM. For the implementation in REMIND, the short-term storage capacities calculated by DIMES are also parameterized by a thirdorder polynomial depending on wind and PV shares, and input as requirements into REMIND. While this required investment into storage results in additional costs to the electricity system, it also leads to an RLDC with reduced curtailment and reduced peak demand, as can be seen in Figure 11. 
In contrast, long-term/seasonal storage can be endogenously represented with the help of the RLDC, because it relies on filling and emptying the reservoir only once per year. The model can use curtailed electricity from the right of the RLDC to produce hydrogen, which then can either be used in other sectors or in hydrogen turbines to provide dispatchable generation at times of high residual demand.

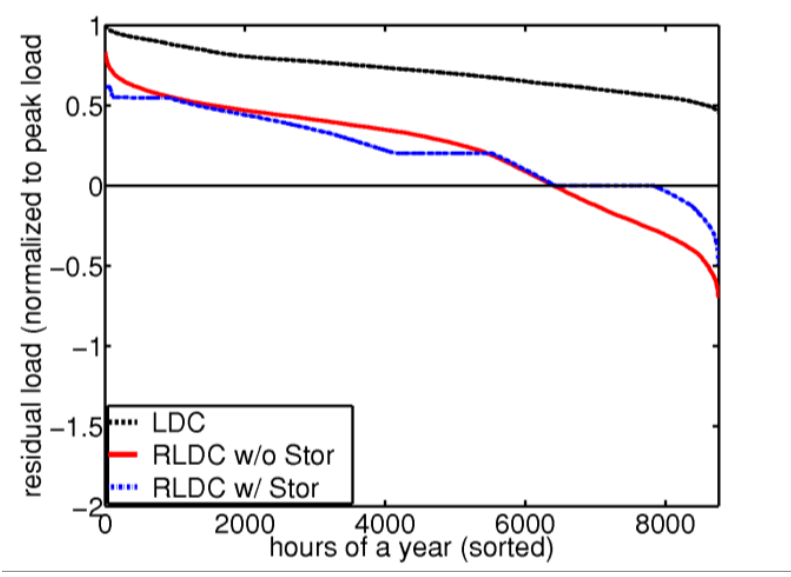

Figure 11: Effect of short-term storage deployment in DIMES on the RLDC for Europe with a gross contribution (gross meaning "before curtailments") to a load of $30 \%$ from wind and $40 \%$ from PV. The LDC is displayed in black. Compared to the RLDC before use of short-term storage (red), the RLDC with storage (blue) shows much lower residual peak demand and less curtailment.

\section{Advantages and Limitations}

The main advantage of the RLDC-approach is the reduction of complexity through pre-processing of load and VRE generation time series. This enables a decent representation of the power system with a relatively small number of parameters: six variables, each represented by a third-order polynomial, capture the most important power sector characteristics, as shown by a comparison of REMIND results with the hourly power sector model REMIX [24].

There are, however, a number of limitations to this methodology:

- Due to the loss of chronology, short-term flexibility (ramping) constraints cannot be explicitly represented. However, as the RLDC captures the shift to low capacity factors at high shares of VRE, it will result in power systems with high amounts of low-capital cost power plants such as gas or hydrogen combustion turbines, which should ensure sufficient flexibility.

- There are also issues regarding the spatial aspect of VRE integration (pooling, impact of grid extensions) in that these effects cannot be calculated from RLDCs, but rather need to be accounted for already in the original data from which the RLDCs were derived.

- While the effect of using short-term storage cannot be directly calculated from the RLDC in REMIND itself, it was be implemented in an approximate way through a pre-processing step: cost-optimal storage capacities at different wind and solar shares are calculated with the help of a smaller dispatch and investment model with high temporal resolution, and this 
information is basis for the REMIND investments into VRE, storage, and dispatchable capacities.

\section{Discussion and Conclusions}

The aim of this work was to review the current state of play with regards to how integration challenges of VRES are represented in ESOMs and IAMs. A key motivator in this was to aid future research by presenting and contrasting these methodologies so that, in future, energy system modellers can select and apply methodologies best suited to their situation. Failure to sufficiently capture the integration challenges of VRES can lead to unrealistic assessment of the difficulty associated with achieving a low carbon energy system and thus lead to sub-optimal energy system planning.

The presented methodologies all have their own strengths and limitations but also differ in their ease of use. To aid the discussion, Table 1 presents an overview of the different methodologies and their respective advantages and disadvantages.

\begin{tabular}{|c|c|c|c|}
\hline \multicolumn{2}{|l|}{ Methodology } & \multirow{2}{*}{$\begin{array}{l}\text { Strengths } \\
\text { - } \quad \text { Accurate assessment of operational costs, } \\
\text { fuel consumption and greenhouse gas } \\
\text { emissions } \\
\text { - High level of temporal and technical detail } \\
\text { allows assessment of power system } \\
\text { reliability. } \\
\text { Good robustness check of energy system } \\
\text { model results }\end{array}$} & \multirow{2}{*}{$\begin{array}{l}\text { Limitations and challenges } \\
\text { - } \quad \text { Need for a UCED model in addition to } \\
\text { the ESOM/IAM } \\
\text { Does not increase the optimality of the } \\
\text { solution: } \\
\text { Can possibly overestimate integration } \\
\text { costs of VRES, because the ESOM } \\
\text { investments are not adjusted to } \\
\text { account for the UCED challenges }\end{array}$} \\
\hline & $\begin{array}{l}\text { Uni-directional soft- } \\
\text { link }\end{array}$ & & \\
\hline $\begin{array}{l}\text { Soft-link to an operational power } \\
\text { system model }\end{array}$ & $\begin{array}{l}\text { Bi-directional soft- } \\
\text { link }\end{array}$ & $\begin{array}{l}\text { - } \quad \text { Allows for increased optimality of the } \\
\text { solution } \\
\text { Iterative procedure has a lower } \\
\text { computational cost than a single } \\
\text { integrated ESOM/IAM with the same level } \\
\text { of detail } \\
\text { - } \quad \text { Accurate assessment of costs, fuel } \\
\text { consumption and greenhouse gas } \\
\text { emissions } \\
\text { High level of temporal and technical detail } \\
\text { allows assessment of power system } \\
\text { reliability. } \\
\text { Good robustness check of energy system } \\
\text { model results }\end{array}$ & $\begin{array}{l}\text { - } \quad \text { Need for a UCED model in addition to } \\
\text { the ESOM/IAM } \\
\text { - Feedback to ESOM/IAM highly } \\
\text { dependent on modeller skill and } \\
\text { judgement } \\
\text { Optimality and convergence of the } \\
\text { solution cannot be guaranteed }\end{array}$ \\
\hline \multirow[t]{2}{*}{$\begin{array}{l}\text { Direct integration methodologies for } \\
\text { ESOMs }\end{array}$} & $\begin{array}{l}\text { Semi-dynamic } \\
\text { balancing using } \\
\text { typical days with } \\
\text { increased } \\
\text { resolution }\end{array}$ & $\begin{array}{l}\text { - } \\
\text { - } \text { solutions for increased optimality of the } \\
\text { - } \quad \text { Ease of implementation } \\
\text { Retains chronology which allows the } \\
\text { capture of the benefits associated with } \\
\text { within-day storage systems and other } \\
\text { types of flexibility }\end{array}$ & 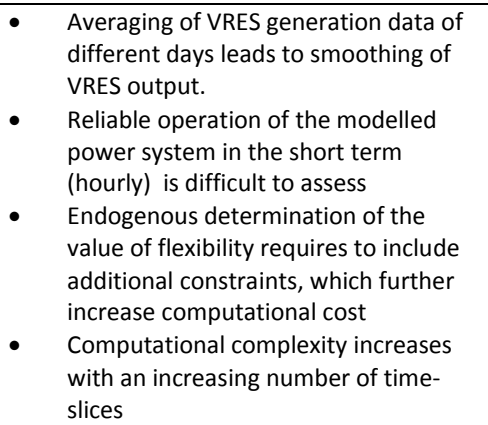 \\
\hline & $\begin{array}{l}\text { Integral balancing } \\
\text { based on } \\
\text { approximating the } \\
\text { joint probability } \\
\text { distribution of the } \\
\text { load and VRES }\end{array}$ & $\begin{array}{l}\text { - } \\
\text { - } \\
\text { sollows for increased optimality of the } \\
\text { The variability of the load and VRES } \\
\text { generation can be captured relatively well } \\
\text { using a limited number of time-slices } \\
\text { The correlation between different time } \\
\text { series is accounted for. This way, the RLDC }\end{array}$ & $\begin{array}{l}\text { - Chronology is lost making it impossible } \\
\text { to assess the need for flexibility and } \\
\text { the value of flexibility options } \\
\text { Reliable operation of the modelled } \\
\text { power system in the short term } \\
\text { (hourly) is difficult to assess }\end{array}$ \\
\hline
\end{tabular}




\begin{tabular}{|c|c|c|c|}
\hline & generation & $\begin{array}{l}\text { will be approximated well for varying } \\
\text { shares of VRES. } \\
\text { Ease of implementation }\end{array}$ & \\
\hline & $\begin{array}{l}\text { Semi-dynamic } \\
\text { balancing using } \\
\text { representative } \\
\text { historical periods }\end{array}$ & $\begin{array}{l}\text { - } \quad \text { Allows the strong increase of the } \\
\text { optimality of the solution } \\
\text { The variability of the load and VRES } \\
\text { generation can be captured well using a } \\
\text { limited number of time-slices } \\
\text { - The correlation between different time } \\
\text { series can be accounted for. This way, the } \\
\text { RLDC will be approximated well for } \\
\text { varying shares of VRES. } \\
\text { Retains chronology which allows an } \\
\text { endogenous determination of the value of } \\
\text { flexibility options such as within-day } \\
\text { storage. }\end{array}$ & $\begin{array}{l}\text { Reliable operation of the modelled } \\
\text { power system in the short term } \\
\text { (hourly) is difficult to assess } \\
\text { Good selection of representative } \\
\text { historical periods requires } \\
\text { implementation of a specific selection } \\
\text { algorithm/model } \\
\text { Difficult to capture the impact of } \\
\text { medium-term variations (e.g., periods } \\
\text { of two weeks with almost no wind) } \\
\text { Endogenous determination of the } \\
\text { value of flexibility requires to include } \\
\text { additional constraints, which further } \\
\text { increase computational cost }\end{array}$ \\
\hline & $\begin{array}{l}\text { Using stochastic } \\
\text { programming as a } \\
\text { means to address } \\
\text { modelling } \\
\text { uncertainties }\end{array}$ & $\begin{array}{l}\text { - } \quad \text { The requirement for back-up capacity is } \\
\text { endogenous removing the need for a } \\
\text { commonly used peak constraint. } \\
\text { Hedges against not having enough } \\
\text { flexibility generation capacity in the power } \\
\text { system. } \\
\text { - } \quad \text { Detailed quantification of uncertainty } \\
\text { Can be combined with methodologies that } \\
\text { increase intra-annual time resolution } \\
\text { - Can incorporate several historical RES } \\
\text { profiles } \\
\text { Measures the costs of disregarding } \\
\text { uncertainty } \\
\text { Measures the cost of eliminating } \\
\text { uncertainty (and hence provides insights } \\
\text { about the order of magnitude of supports } \\
\text { required in investments in back-up } \\
\text { capacity and storage options) }\end{array}$ & $\begin{array}{l}\text { - Strongly increases computational } \\
\text { complexity } \\
\text { Stochastic modelling requires a } \\
\text { representation of the uncertain } \\
\text { parameters that are specific to the } \\
\text { model used } \\
\text { Requires advanced scenario tree } \\
\text { generation techniques and reduction } \\
\text { algorithms } \\
\text { Requires a solid understanding of } \\
\text { probability concepts and sampling } \\
\text { techniques } \\
\text { Can impose difficulties in interpreting } \\
\text { the results obtained }\end{array}$ \\
\hline & $\begin{array}{l}\text { Stylized integration } \\
\text { of operational } \\
\text { constraints }\end{array}$ & 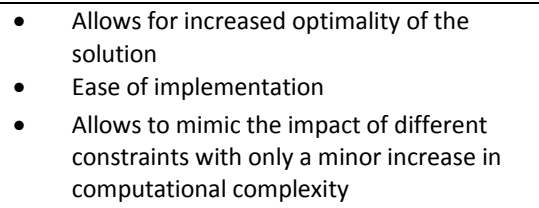 & $\begin{array}{ll} & \text { Requires calibration using more } \\
\text { detailed models } \\
\text { - } & \text { General validity cannot be guaranteed }\end{array}$ \\
\hline & $\begin{array}{l}\text { Modelling ancillary } \\
\text { services markets in } \\
\text { long-term energy } \\
\text { system models }\end{array}$ & 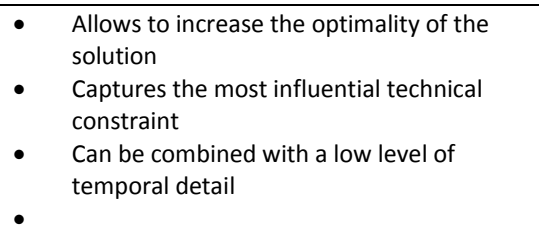 & $\begin{array}{l}\text { Uncertainties related to endogenous } \\
\text { sizing the need for operating reserves } \\
\text { over long time horizons } \\
\text { Requires using additional variables and } \\
\text { constraints which increase } \\
\text { computational complexity }\end{array}$ \\
\hline $\begin{array}{l}\text { Direct integration methodologies for } \\
\text { IAMs }\end{array}$ & $\begin{array}{l}\text { Parametrization of } \\
\text { residual load } \\
\text { duration curves }\end{array}$ & 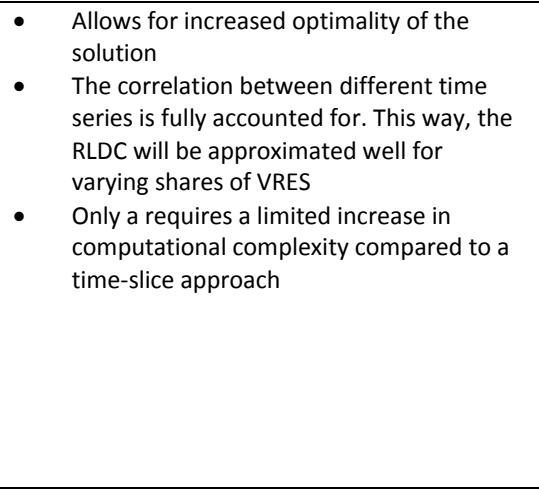 & $\begin{array}{l}\text { - Chronology is lost, making it } \\
\text { impossible to directly assess the need } \\
\text { for flexibility and the value of flexibility } \\
\text { options } \\
\text { Parametrization of the impact of } \\
\text { short-term storage requires pre- } \\
\text { processing of the RLDC using a more } \\
\text { detailed model } \\
\text { The spatial aspect of VRE integration } \\
\text { (effect of transmission grid on pooling } \\
\text { variability) cannot be endogenously } \\
\text { calculated, but rather needs to be } \\
\text { included in the RLDC data ex-ante. } \\
\text { Reliable operation of the modelled } \\
\text { power system in short-term (hourly) is }\end{array}$ \\
\hline
\end{tabular}




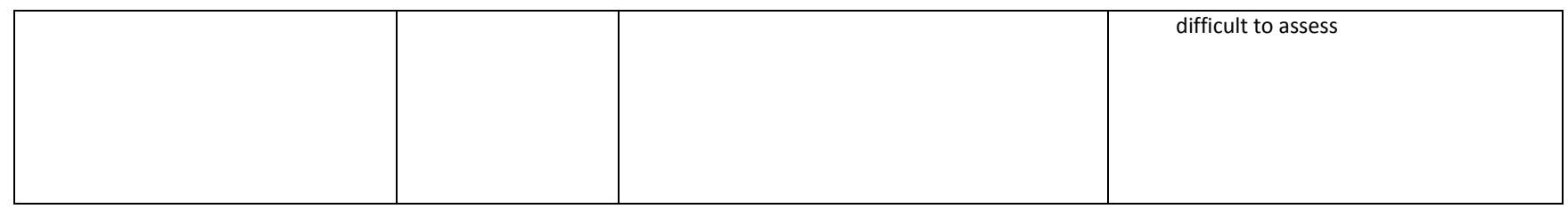

Table 1 - Tabular comparison of modelling methodologies

Indirect soft linking approaches require the construction of new dedicated sectoral models and more challengingly -handling the interface between the two models in order to arrive at consistent results. This allows for a good robustness check of energy system model results by leveraging the strengths of an operational power system model to gain additional insights into long term energy system model results. If it is a bi-directional soft-link then it also allows for increased optimality of the solution. The use of operational modelling means that also better assessment of operational costs, fuel consumption, greenhouse gas emissions and power system reliability is possible.

A key strength of direct integration methodologies for ESOMs and IAMs discussed in this work is that are directly integrated into the model optimisation thus eliminating the need for an iterative approach as is required in the bidirectional soft-link approach. A key strength of such approaches improving the temporal representation in ESOMs is that they all allow for the better capture of variability of load and VRES generation. The use of stochastic programming and probability derived temporal representation also helps ensure that a wide range of possible outcomes are captured in the model optimisation, this makes the power system more robust in relation to modelling uncertainties. A common limitation of these approaches is that operation of the modelled power system in the short term remains difficult to assess, this is also true of the approach outlined for IAMs. The direct integration methodologies for ESOMs that improve the technical representation directly increase the optimality of solution. The stylized integration of operation constraints are easy to implement and the integration of ancillary services markets in ESOMs allow the capture of a very influential technical constraint on system operation. Generally, the challenge of the use of such approaches is that they require careful calibration to ensure validity and not doing so can lead to inaccurate assessment of VRES integration potential. In IAMs, the parameterization of RLDCs are effective in representing correlation between different time series thus making the RLDC well approximated well for varying shares of VRES while requiring only a limited increase in computational complexity. Loss of chronology makes it impossible for it to directly assess the value of flexibility measures and to thus assess the value of short term storage requires use of a separate more detailed model. This approach for IAMs also cannot endogenously capture the spatial element of VRES integration meaning it needs to be included in the RLDC data ex-ante.

From this review it is evident that there are clear advantages and disadvantages to all the approaches discussed. Thus, it is apparent that the choice of methodology is highly dependent on the modelling situation to which it is to be applied regarding the models used, modeller skill and data availability. This work, by comparing a whole variety of approaches and identifying their strengths and limitations, helps modellers in their selection of a methodology best suited to them.

There are certain principals that have been identified as guides for addressing flexibility in energy models such as careful consideration of model simplifications, definition of appropriate temporal and geographic resolution, definition of system flexibility constraints and model validation [36]. The inherent differences between the methodologies mean that each will integrate short term variations 
differently into the modelling process and assess the flexibility of the system differently. To date these methodologies have been applied successfully to separate models and data sets, making it difficult to compare results. Future work is required to effectively compare strengths and weaknesses of the different approaches, this is a key hotspot for future research in this area.

There are a number of avenues down which such research could be furthered. Any such work comparing methodologies should apply methodologies to the same region using the same data sets in order to increase comparability and reduce own-model bias in the evaluation. An example of such work are studies to directly compare methodologies that directly improve the temporal \& technical representation respectively within long term planning models. This would quantify directly the trade-offs made when selecting a methodology to apply. Other work could be done to analyse the impact of improving the technical \& technical representation of models in tandem. This could be done by applying various levels of technical representation in the model and coupling these additions with various levels of temporal representation. Such work would provide clarity on how the implementation of certain methodologies impact on one another and also how impactful certain technical elements become under various temporal representations in long term models and vice versa. These suggestions for future work would also benefit from uni-directional or bi-directional soft-linking which could operationally analyse under high resolution the various power sectors projected and give insights into their operational realisation. Such analysis would provide clarity on the variety of results achieved by the different methodologies and lead to better estimation of the effort required to transition to an energy system with high proportions of renewable power generation which would, in turn, lead to better informed development of energy policy.

\section{Acknowledgements}

Seán Collins and Kris Poncelet would like to express gratitude for the PhD scholarships from the SFI centre MaREI (12/RC/2302) Platform 4 and Flemish Institute of Technological Research (VITO) respectively.

\section{Contributions}

All authors developed the concept for the review. Seán Collins developed the first draft of the manuscript with contributions from Kris Poncelet, Evangelos Panos and Robert Pietzcker. All authors discussed the results and further developed the manuscript.

\section{References}

[1] ECF. Roadmap 2050 - Technical \& Economic Analysis - Full Report. European Climate Foundation; 2010.

[2] EC. Energy Roadmap 2050 COM(2011) 885 final. 2011.

[3] IEA. World energy outlook 2012.

[4] Luderer G, Krey V, Calvin K, Merrick J, Mima S, Pietzcker R, et al. The role of renewable energy in climate stabilization: results from the EMF27 scenarios. Climatic change. 2014;123:427-41.

[5] Holttinen $\mathrm{H}$. The impact of large scale wind power production on the Nordic electricity system:

VTT Technical Research Centre of Finland; 2004.

[6] Holttinen H, Meibom P, Orths A, Van Hulle F, Lange B, O'Malley M, et al. Design and operation of power systems with large amounts of wind power: Final report, Phase one 2006-08, IEA WIND Task 25: VTT; 2009. 
[7] IEA. Energy technology perspectives. International Energy Agency; 2012.

[8] Eurelectric. Flexible generation: Backing up renewables.

http://www.eurelectric.org/media/61388/flexibility_report_final-2011-102-0003-01-e.pdf2011.

[9] Müller S, Sisternes Fd, Patriarca E, Portellano A, Göritz A, Møller JD, et al. The Power of Transformation - Wind, Sun and the Economics of Flexible Power Systems.

https://www.iea.org/publications/freepublications/publication/the-power-of-transformation--wind-sun-and-the-economics-of-flexible-power-systems.html: IEA; 2014.

[10] Poncelet K, Delarue E, Six D, Duerinck J, D'haeseleer W. Impact of the level of temporal and operational detail in energy-system planning models. Applied Energy. 2016;162:631-43.

[11] Deane JP, Chiodi A, Gargiulo M, Ó Gallachóir BP. Soft-linking of a power systems model to an energy systems model. Energy. 2012;42:303-12.

[12] Haydt G, Leal V, Pina A, Silva CA. The relevance of the energy resource dynamics in the $\mathrm{mid} /$ long-term energy planning models. Renewable energy. 2011;36:3068-74.

[13] Ludig S, Haller M, Schmid E, Bauer N. Fluctuating renewables in a long-term climate change mitigation strategy. Energy. 2011;36:6674-85.

[14] Pina A, Silva CA, Ferrão P. High-resolution modeling framework for planning electricity systems with high penetration of renewables. Applied Energy. 2013;112:215-23.

[15] Kannan R, Turton H. A long-term electricity dispatch model with the TIMES framework. Environmental Modeling \& Assessment. 2013;18:325-43.

[16] De Sisternes FJ, Webster MD. Optimal selection of sample weeks for approximating the net load in generation planning problems. Massachusetts Institute of Technology Engineering Systems Division Working Paper Series: Citeseer; 2013. p. 1-12.

[17] Palmintier B. Flexibility in generation planning: Identifying key operating constraints. Power Systems Computation Conference (PSCC), 2014: IEEE; 2014. p. 1-7.

[18] Nweke Cl, Leanez F, Drayton GR, Kolhe M. Benefits of chronological optimization in capacity planning for electricity markets. Power System Technology (POWERCON), 2012 IEEE International Conference on: IEEE; 2012. p. 1-6.

[19] Welsch M, Deane P, Howells M, Gallachóir BÓ, Rogan F, Bazilian M, et al. Incorporating flexibility requirements into long-term energy system models - A case study on high levels of renewable electricity penetration in Ireland. Applied Energy. 2014;135:600-15.

[20] van Stiphout A, Poncelet K, De Vos K, Deconinck G. The impact of operating reserves on investment planning of renewable power systems. Accepted for publication in IEEE Transactions on Power Systems. 2016.

[21] Zeyringer M, Fais B, Price J, . "New" or "old" technologies to decarbonize UK's electricity system? A long- term high spatial and temporal resolution assessment for marine and wind energy. 13th International Conference on the European Energy Market (EEM). Porto2016.

[22] Koltsaklis NE, Dagoumas AS, Kopanos GM, Pistikopoulos EN, Georgiadis MC. A spatial multiperiod long-term energy planning model: A case study of the Greek power system. Applied Energy. 2014;115:456-82.

[23] Biberacher M, Gadocha S, van Vliet O. Global Energy System Modelling linked to spatial data with focus on renewable energy resources-a case study. Envirolnfo2013. p. 47-54.

[24] Pietzcker RC, Ueckerdt F, Carrara S, De Boer H-S, Després J, Fujimori S, et al. System integration of wind and solar power in Integrated Assessment Models: a cross-model evaluation of new approaches. Submitted to Energy Economics. 2016.

[25] Milligan MR, Miller AH, Chapman F. Estimating the economic value of wind forecasting to utilities. Windpower '95. Washington, D.C.: NREL; 1995.

[26] Eto $\mathrm{JH}$. Use of frequency response metrics to assess the planning and operating requirements for reliable integration of variable renewable generation. Lawrence Berkeley National Laboratory. 2011.

[27] Undrill J. Power and Frequency Control as it Relates to Wind-Powered Generation. 2010. 
[28] Ekanayake J, Jenkins N. Comparison of the response of doubly fed and fixed-speed induction generator wind turbines to changes in network frequency. IEEE Transactions on Energy Conversion. 2004;19:800-2.

[29] Yingcheng $X$, Nengling T. Review of contribution to frequency control through variable speed wind turbine. Renewable Energy. 2011;36:1671-7.

[30] Pfenninger S, Hawkes A, Keirstead J. Energy systems modeling for twenty-first century energy challenges. Renewable and Sustainable Energy Reviews. 2014;33:74-86.

[31] Foley A, Smyth BM, Pukšec T, Markovska N, Duić N. A review of developments in technologies and research that have had a direct measurable impact on sustainability considering the Paris agreement on climate change. Renewable and Sustainable Energy Reviews. 2017;68, Part 2:835-9. [32] Wang Z, Li Y. Layer pattern thermal design and optimization for multistream plate-fin heat exchangers-A review. Renewable and Sustainable Energy Reviews. 2016;53:500-14.

[33] Budzianowski WM, Postawa K. Renewable energy from biogas with reduced carbon dioxide footprint: Implications of applying different plant configurations and operating pressures.

Renewable and Sustainable Energy Reviews. 2017;68, Part 2:852-68.

[34] Lefebvre D, Tezel FH. A review of energy storage technologies with a focus on adsorption thermal energy storage processes for heating applications. Renewable and Sustainable Energy Reviews. 2017;67:116-25.

[35] Shareef $\mathrm{H}$, Islam MM, Mohamed A. A review of the stage-of-the-art charging technologies, placement methodologies, and impacts of electric vehicles. Renewable and Sustainable Energy Reviews. 2016;64:403-20.

[36] Hidalgo Gonzalez I, RUIZ CASTELLO P, SGOBBI A, NIJS W, Quoilin S, ZUCKER A, et al. Addressing flexibility in energy system models: Publications Office of the European Union; 2015.

[37] IRENA. Planning for the renewable future: Long-term modelling and tools to expand variable renewable power in emerging economies 2017.

[38] Connolly D, Lund H, Mathiesen BV, Leahy M. A review of computer tools for analysing the integration of renewable energy into various energy systems. Applied Energy. 2010;87:1059-82.

[39] Energy-Exemplar. PLEXOS ${ }^{\circledR}$ Integrated Energy Model.

http://energyexemplar.com/software/plexos-desktop-edition/2013.

[40] Van den Bergh K, Bruninx K, Delarue E, D'haeseleer W. LUSYM: a unit commitment model formulated as a mixed-integer linear program.

https://www.mech.kuleuven.be/en/tme/research/energy_environment/Pdf/wpen2014-07-2.pdf, : University Leuven TME Working Paper. WP EN2014-07 Available at $<$ www. mech. kuleuven.

be/en/tme/research/energy_environment; 2016.

[41] Veselka T, Novickas A. Generation and Transmission Maximization (GTMax) Model Users Guide. Argonne National Laboratory, Chicago, IL. 2001.

[42] Hadley SW. The Oak Ridge Competitive Electricity Dispatch (ORCED) Model. ORNL/TM2007/230, Oak Ridge National Laboratory, June. 2008.

[43] Lund $\mathrm{H}$. EnergyPLAN-Advanced Energy Systems Analysis Computer Model-Documentation Version 12 -http://www. energyPLAN. eu. Aalborg University, Aalborg, Denmark. 2015.

[44] Loulou R, Remme U, Kanudia A, Lehtila A, Goldstein G. Documentation for the TIMES Model. Energy Technology Systems Analysis Programme (ETSAP). 2005.

[45] AGENCY IAE. Modelling Nuclear Energy Systems with MESSAGE: A User's Guide. Vienna: INTERNATIONAL ATOMIC ENERGY AGENCY; 2016.

[46] Scholz Y, Gils HC, Pietzcker R. Application of a high-detail energy system model to derive power sector characteristics at high wind and solar shares. Energy Economics. 2016.

[47] ETSAP. http://www.iea-etsap.org/web/applicationGlobal.asp 2016.

[48] UCL. https://www.ucl.ac.uk/energy-models/models/tiam-ucl/\#etsap-tiam. 2016.

[49] Messner S, Schrattenholzer L. MESSAGE-MACRO: linking an energy supply model with a macroeconomic module and solving it iteratively. Energy. 2000;25:267-82. 
[50] Moss RH, Edmonds JA, Hibbard KA, Manning MR, Rose SK, Van Vuuren DP, et al. The next generation of scenarios for climate change research and assessment. Nature. 2010;463:747-56.

[51] Clarke L, Jiang K, Akimoto K, Babiker M, Blanford G, Fisher-Vanden K, et al. Assessing transformation pathways. 2014.

[52] Messner S, Strubegger M. User's Guide for MESSAGE III. Rep WP-95-69, International Institute for Applied Systems Analysis, Laxenburg, Austria. 1995;14.

[53] www.eie.gov.tr/projeler/document/5_POLES_description.pdf.

[54] Stehfest E, van Vuuren D, Bouwman L, Kram T. Integrated assessment of global environmental change with IMAGE 3.0: Model description and policy applications: Netherlands Environmental Assessment Agency (PBL); 2014.

[55] http://www.globalchange.umd.edu/archived-models/gcam/.

[56] Fujimori S, Masui T, Matsuoka Y. AIM/CGE [basic] manual. Center for Social and Environmental Systems Research, NIES: Tsukuba, Japan. 2012.

[57] Manne AS, Richels RG. MERGE: an integrated assessment model for global climate change.

Energy and environment: Springer; 2005. p. 175-89.

[58] http://globalchange.mit.edu/research/IGSM/eppadl.

[59] Bosetti V, Massetti E, Tavoni M. The WITCH model: structure, baseline, solutions. 2007.

[60] Luderer G, Leimbach M, Bauer N, Kriegler E, Baumstark L, Bertram C, et al. Description of the Remind Model (Version 1.6). papersssrncom. 2015.

[61] Carrara S, Marangoni G. Including System Integration of Variable Renewable Energies in a Constant Elasticity of Substitution Framework: the Case of the WITCH Model. 2016.

[62] Sullivan P, Krey V, Riahi K. Impacts of considering electric sector variability and reliability in the MESSAGE model. Energy Strategy Reviews. 2013;1:157-63.

[63] De Boer HS, Van Vuuren DP. Representation of variable renewable energy sources in TIMER, an aggregated energy system simulation model. Accepted at Energy Economics. 2016.

[64] Pietzcker RC, Stetter D, Manger S, Luderer G. Using the sun to decarbonize the power sector: The economic potential of photovoltaics and concentrating solar power. Applied Energy.

2014;135:704-20.

[65] Chiodi A. Climate and energy scenarios for Ireland to 2050 using the Irish TIMES energy systems model. 2014.

[66] GAGO DCSS, NIJS W, RUIZ CP, SGOBBI A, RADU D, BOLAT P, et al. The JRC-EU-TIMES model-

Assessing the long-term role of the SET Plan Energy technologies: Publications Office of the

European Union; 2013.

[67] Rosen J, Tietze-Stöckinger I, Rentz O. Model-based analysis of effects from large-scale wind power production. Energy. 2007;32:575-83.

[68] Welsch M, Howells M, Hesamzadeh MR, Ó Gallachóir B, Deane P, Strachan N, et al. Supporting security and adequacy in future energy systems: The need to enhance long-term energy system models to better treat issues related to variability. International Journal of Energy Research. 2015;39:377-96.

[69] Deane J, Gracceva F, Chiodi A, Gargiulo M, Gallachóir BÓ. Soft-Linking Exercises Between TIMES, Power System Models and Housing Stock Models. Informing Energy and Climate Policies Using Energy Systems Models: Springer; 2015. p. 315-31.

[70] Deane J, Gracceva F, Chiodi A, Gargiulo M, Gallachóir BP. Assessing power system security. A framework and a multi model approach. International Journal of Electrical Power \& Energy Systems. 2015;73:283-97.

[71] Brouwer AS, van den Broek M, Seebregts A, Faaij A. Operational flexibility and economics of power plants in future low-carbon power systems. Applied Energy. 2015;156:107-28.

[72] Young D, Blanford G, Niemeyer V. Program on Technology Innovation: US-REGEN Model Documentation.

http://www.epri.com/abstracts/Pages/ProductAbstract.aspx?Productld=000000003002004748: EPRI; 2015. 
[73] Després J, Mima S, Kitous A, Criqui P, Hadjsaid N, Noirot I. Storage as a flexibility option in power systems with high shares of variable renewable energy sources: a POLES-based analysis. Energy Economics. 2016.

[74] Loulou R, Remme U, Kanudia A, Lehtila A, Goldstein G. Documentation for the TIMES Model Part I. Energy technology systems analysis programme (ETSAP). 2005.

[75] Nahmmacher P, Schmid E, Hirth L, Knopf B. Carpe diem: a novel approach to select representative days for long-term power system models with high shares of renewable energy sources. papersssrncom. 2014.

[76] Poncelet K, Höschle H, Delarue E, Virag A, D'haeseleer W. Selecting representative days for investment planning models Accepted for publication in IEEE transactions on power systems DOI: 101109/TPWRS20162596803. 2016.

[77] Pina A, Silva C, Ferrão P. Modeling hourly electricity dynamics for policy making in long-term scenarios. Energy Policy. 2011;39:4692-702.

[78] Kannan R, Turton H, Panos E. Methodological Significance of Temporal Granularity in EnergyEconomic Models-Insights from the MARKAL/TIMES Framework. Informing Energy and Climate Policies Using Energy Systems Models: Springer; 2015. p. 185-200.

[79] Kannan R, Turton H. Documentation on the development of the Swiss TIMES Electricity Model (STEM-E). Paul Scherrer Institute (PSI); 2011.

[80] Lehtveer M, Mattsson N, Hedenus F, Soini M. Using Resource Based Slicing to Capture the Intermittency of Variable Renewables, : Chalmers University http://publications.lib.chalmers.se/publication/238707; 2016.

[81] Haller M, Ludig S, Bauer N. Decarbonization scenarios for the EU and MENA power system: Considering spatial distribution and short term dynamics of renewable generation. Energy Policy. 2012;47:282-90.

[82] Kirschen DS, Ma J, Silva V, Belhomme R. Optimizing the flexibility of a portfolio of generating plants to deal with wind generation. Power and Energy Society General Meeting, 2011 IEEE: IEEE; 2011. p. 1-7.

[83] Belderbos A, Delarue E. Accounting for flexibility in power system planning with renewables. International Journal of Electrical Power \& Energy Systems. 2015;71:33-41.

[84] Fripp M. Switch: a planning tool for power systems with large shares of intermittent renewable energy. Environmental science \& technology. 2012;46:6371-8.

[85] Neuhoff K, Ehrenmann A, Butler L, Cust J, Hoexter H, Keats K, et al. Space and time: Wind in an investment planning model. Energy Economics. 2008;30:1990-2008.

[86] EINozahy M, Salama M, Seethapathy R. A probabilistic load modelling approach using clustering algorithms. Power and Energy Society General Meeting (PES), 2013 IEEE: IEEE; 2013. p. 1-5.

[87] Fazlollahi S, Bungener SL, Mandel P, Becker G, Maréchal F. Multi-objectives, multi-period optimization of district energy systems: I. Selection of typical operating periods. Computers \& Chemical Engineering. 2014;65:54-66.

[88] Omran WA, Kazerani M, Salama M. A clustering-based method for quantifying the effects of large on-grid PV systems. Power Delivery, IEEE Transactions on. 2010;25:2617-25.

[89] Nick M, Cherkaoui R, Paolone M. Optimal allocation of dispersed energy storage systems in active distribution networks for energy balance and grid support. Power Systems, IEEE Transactions on. 2014;29:2300-10.

[90] Nahmmacher P, Schmid E, Knopf B. Documentation of LIMES-EU-A long-term electricity system model for Europe. preparation; 2014.

[91] Mantzos L, Wisenthal T, Kourti J, Matei N, Navajas W, Papafragkou A, et al. POTEnClA model description - version 0.9. 2016.

[92] Dantzig GB. Linear programming under uncertainty. Management science. 1955;1:197-206. [93] Wallace SW, Fleten S-E. Stochastic programming models in energy. Handbooks in operations research and management science. 2003;10:637-77. 
[94] Usher W, Strachan N. Critical mid-term uncertainties in long-term decarbonisation pathways.

Energy Policy. 2012;41:433-44.

[95] Keppo I, van der Zwaan B. The impact of uncertainty in climate targets and CO2 storage availability on long-term emissions abatement. Environmental Modeling \& Assessment.

2012;17:177-91.

[96] Ahmed S. Two-Stage Stochastic Integer Programming: A Brief Introduction. Wiley Encyclopedia of Operations Research and Management Science. 2010.

[97] Loulou R, Lehtila A. Stochastic programming and tradeoff analysis in TIMES. IEA ETSAP TIMES version. 2007;2.

[98] Seljom P, Tomasgard A. Short-term uncertainty in long-term energy system models-A case study of wind power in Denmark. Energy Economics. 2015;49:157-67.

[99] Høyland K, Wallace SW. Generating scenario trees for multistage decision problems.

Management Science. 2001;47:295-307.

[100] Kaut M, Wallace SW. Evaluation of scenario-generation methods for stochastic programming. 2003.

[101] Gröwe-Kuska N, Heitsch H, Römisch W. Scenario reduction and scenario tree construction for power management problems. Power Tech Conference Proceedings, 2003 IEEE Bologna: IEEE; 2003. p. 7 pp. Vol. 3.

[102] Birge JR. The value of the stochastic solution in stochastic linear programs with fixed recourse. Mathematical programming. 1982;24:314-25.

[103] van der Weijde AH, Hobbs BF. The economics of planning electricity transmission to accommodate renewables: Using two-stage optimisation to evaluate flexibility and the cost of disregarding uncertainty. Energy Economics. 2012;34:2089-101.

[104] Palmintier B, Webster M. Impact of unit commitment constraints on generation expansion planning with renewables. Power and Energy Society General Meeting, 2011 IEEE: IEEE; 2011. p. 1-7. [105] De Jonghe C, Delarue E, Belmans R, D'haeseleer W. Determining optimal electricity technology mix with high level of wind power penetration. Applied Energy. 2011;88:2231-8.

[106] Hirth L. The market value of variable renewables: The effect of solar wind power variability on their relative price. Energy Economics. 2013;38:218-36.

[107] Short W, Sullivan P, Mai T, Mowers M, Uriarte C, Blair N, et al. Regional energy deployment system (ReEDS). Contract. 2011;303:275-3000.

[108] Devogelaer D, Duerinck J, Gusbin D, Marenne Y, Nijs W, Orsini M, et al. Towards $100 \%$ renewable energy in Belgium by 2050. Belgium: FPB, ICEDD, VITO. 2012:156.

[109] Panos E, Lehtilä A. Dispatching and Unit Commitment Features in TIMES. Presentation. 69th ETSAP Workshop, University College Cork, 30-31 May 2016. 2016.

[110] Rebours Y, Kirschen D. A survey of definitions and specifications of reserve services. Report, University of Manchester. 2005.

[111] Vögelin P, Georges G, Noembrini F, Koch B, Boulouchos K, Buffat R, et al. System modelling for assessing the potential of decentralised biomass-CHP plants to stabilise the Swiss electricity network with increased fluctuating renewable generation.

http://www.bfe.admin.ch/php/modules/enet/streamfile.php?file=000000011337.pdf 2016.

[112] Hirth L, Ziegenhagen I. Balancing power and variable renewables: Three links. Renewable and Sustainable Energy Reviews. 2015;50:1035-51.

[113] Doherty R, O'Malley M. A new approach to quantify reserve demand in systems with significant installed wind capacity. IEEE Transactions on Power Systems. 2005;20:587-95.

[114] Ortega-Vazquez MA, Kirschen DS. Estimating the spinning reserve requirements in systems with significant wind power generation penetration. IEEE Transactions on Power Systems.

2009;24:114-24.

[115] Hodge B-M, Florita A, Orwig K, Lew D, Milligan M. A comparison of wind power and load forecasting error distributions. 2012 World Renewable Energy Forum2012. p. 13-7.

[116] Freedman DA. Statistical models: theory and practice: cambridge university press; 2009. 
[117] Socha L. Linearization methods for stochastic dynamic systems: Springer Science \& Business Media; 2007.

[118] Strbac G. Quantifying the system costs of additional renewables in 2020. DTI report. 2002. [119] Koltsaklis NE, Georgiadis MC. A multi-period, multi-regional generation expansion planning model incorporating unit commitment constraints. Applied Energy. 2015;158:310-31.

[120] Wan Y-H. A primer on wind power for utility applications: National Renewable Energy Laboratory Golden; 2005.

[121] Ueckerdt F, Brecha R, Luderer G, Sullivan P, Schmid E, Bauer N, et al. Representing power sector variability and the integration of variable renewables in long-term energy-economy models using residual load duration curves. Energy. 2015;90:1799-814.

[122] Ueckerdt F, Pietzcker R, Scholz Y, Stetter D, Giannousakis A, Luderer G. Decarbonizing global power supply under region-specific consideration of challenges and options of integrating variable renewables in the REMIND model. Energy Economics. 2016.

[123] Ueckerdt F, Brecha R, Luderer G. Analyzing major challenges of wind and solar variability in power systems. Renewable Energy. 2015;81:1-10.

[124] Johnson N, Strubegger M, McPherson M, Parkinson SC, Krey V, Sullivan P. A reduced-form approach for representing the impacts of wind and solar PV deployment on the structure and operation of the electricity system. . Energy Economics. 2016. 